\title{
Technology Choice and Capacity Portfolios under Emissions Regulation
}

\section{Citation}

Drake, David, Paul R. Kleindorfer, and Luk N. Van Wassenhove. "Technology Choice and Capacity Portfolios under Emissions Regulation." Production and Operations Management 25, no. 6 (June 2016): 1006-1025.

\section{Published Version}

http://onlinelibrary.wiley.com/doi/10.1111/poms.12523/full

\section{Permanent link}

http://nrs.harvard.edu/urn-3:HUL.InstRepos:28538405

\section{Terms of Use}

This article was downloaded from Harvard University's DASH repository, and is made available under the terms and conditions applicable to Open Access Policy Articles, as set forth at http:// nrs.harvard.edu/urn-3:HUL.InstRepos:dash.current.terms-of-use\#OAP

\section{Share Your Story}

The Harvard community has made this article openly available.

Please share how this access benefits you. Submit a story.

Accessibility 


\title{
Technology Choice and Capacity Portfolios under Emissions Regulation
}

\author{
David F. Drake* • Paul R. Kleindorfer** • Luk N. Van Wassenhove** \\ * Harvard Business School, Harvard University, Boston, MA 02163 \\ ** INSEAD, Boulevard de Constance, 77305 Fontainebleau, France \\ Corresponding author: ddrake@hbs.edu
}

\begin{abstract}
We study the impact of emissions tax and emissions cap-and-trade regulation on a firm's technology choice and capacity decisions. We show that emissions price uncertainty under cap-and-trade results in greater expected profit than a constant emissions price under an emissions tax, which contradicts popular arguments that the greater uncertainty under cap-and-trade will erode value. We further show that two operational drivers underlie this result: i) the firm's option not to operate, which effectively right-censors the uncertain emissions price; and ii) dispatch flexibility, which is the firm's ability to first deploy its most profitable capacity given the realized emissions price. In addition to these managerial insights, we also explore policy implications: the effect of emissions price level, and the effect of investment and production subsidies. Through an illustrative example, we show that production subsidies of higher investment and production cost technologies (such as carbon capture and storage technologies) have no effect on the firm's optimal total capacity when firms own a portfolio of both clean and dirty technologies, but that investment subsidies of these technologies increase the firm's total capacity, conditionally increasing expected emissions. A subsidy of a lower production cost technology, on the other hand, has no effect on the firm's optimal total capacity in multi-technology portfolios, regardless of whether the subsidy is a production or investment subsidy.
\end{abstract}

September 30, 2015

\section{Introduction}

Cap-and-trade emissions regulation was implemented in Europe in 2005 under the European Union Emissions Trading Scheme (EU-ETS). Similar legislation has been passed regionally within the US in both California and the Northeast. Meanwhile, a growing chorus of voices that include politicians and economists (Inglis and Laffer 2008), business leaders (Pontin 2010), and climate skeptics (Jowit 2010) have called for an emissions tax regime rather than cap-and-trade. As a result, several bills within the US Congress have proposed national emissions regulation. Some of these have proposed a cap-and-trade mechanism (e.g., H.R. 1666, H.R. 1759, and H.R. 2454), while others have proposed an emissions tax (e.g., H.R. 594, H.R. 1337, and H.R. 2380).

With this activity on the policy front, firms wrestle with how to manage in emissions regulated environments. Given the capital intensity of emissions regulated sectors, investment decisions such as the technologies that firms choose when building capacity are of principal interest. Such decisions 
determine how firms trade off traditional operating and investment costs with emissions intensity (i.e., the emissions generated per unit of production). A firm's emissions intensity determines its exposure to uncertain allowance prices if they are regulated by a cap-and-trade regime, or a constant unit emissions cost under an emissions tax.

Given that firms may choose to operate a single technology or multiple technologies, capacity portfolios are an important aspect of this problem, but an aspect that has largely not been considered within the literature. We study capacity portfolio and production decisions under both an emissions tax and an emissions cap-and-trade regime. We then explore the implications of these decisions, comparing expected profit under both regimes, and assessing the impact of regulatory levers - emissions price level and investment and production subsidies - that can and are employed with the intent of promoting emissions intensity improvement.

Proponents of an emissions tax argue that the uncertainty in emissions price under cap-and-trade erodes firm profits (e.g., Metcalf 2009; Parry and Pizer 2007). However, we show that emissions price uncertainty drives greater expected profit, and we identify the drivers underlying this difference: i) the firm's option not to operate some of its capacity when facing sufficiently great emissions prices; and ii) the flexibility to first dispatch its most profitable capacity given the realized emissions price. We describe each of the necessary and sufficient conditions for the firm to benefit from both of these drivers. Additionally, we explore the efficacy of emissions price level, and investment and production subsidization of clean technology. An important difference between subsidy mechanisms is that investment subsidies decrease a firm's ex ante risk, while production subsidies potentially influence dispatch order. Subsidies, therefore, not only determine whether a technology is included in the firm's optimal portfolio. The choice of subsidy mechanism can affect how a technology is integrated into the portfolio. We illustrate the context-dependent effect this has on total expected emissions through an example grounded in electric power generation.

\section{Relation to the Literature}

There are a number of elements central to a firm's capacity portfolio and production decisions under emissions regulation: i) discrete technologies; ii) capacity investment under uncertainty; iii) production decisions under capacity constraints; and iv) the emissions regulation context. Each of these elements contribute to the results that form the basis for this paper's contribution.

In the Sustainable OM literature that considers technology choice and capacity investment under emissions regulation, Krass et al. (2013) model a Stackelberg game where a regulator sets a tax rate and a firm selects production technology and price. Zhao et al. (2010) explore the impact of allowance allocation schemes in a cap-and-trade setting on equilibrium production under perfect competition. Aflaki and Netessine (2015) explore the effect of intermittent supply on the adoption 
of renewable energy. Drake (2015) and İşlegen et al. (2015) study the effect of regionally asymmetric emissions regulation in models of imperfect competition. Drake (2015) does so with a focus on discrete technology choice and border adjustment without uncertainty, while İşlegen et al. (2015) do so with a focus on the impact of emissions price uncertainty on competition and trade when firms do not have a technology choice. Caro et al. (2013) study joint abatement efforts by supply chain partners (abstracting from production and capacity decisions), finding that emissions must be over-allocated among firms in order to induce optimal abatement effort from each. However, in Krass et al. (2013) and Drake (2015) each firm selects a single technology in deterministic settings. The same is implicitly true in Caro et al. (2013) at the firm-process level. These papers therefore do not consider firms' portfolio decisions and the implications of those decisions, which is our focus here. Also in the Sustainable OM literature and related to our work, Wang et al. (2013) develop a model for capacity investment under an emissions tax and apply that model in a numerical study of Coca-Cola's delivery fleet. While the focus of Wang et al. (2013) is to provide numerical decision support, our focus here is to derive generalizable analytical insights.

Within Economics, the analytic foundation for the discrete technology choice problem with demand uncertainty was laid in Crew and Kleindorfer (1976) in the peak-load pricing literature, which is reviewed in Crew et al. (1993). This framework considers the development of capacity to serve stochastic demand from a finite portfolio of technologies with heterogeneous investment and production costs. As such, the stream is structurally similar to our emissions tax setting, except production costs in our setting include both direct costs as well as unit emissions costs. The latter are determined by the emissions intensity of the technology and the tax rate.

Within Environmental Economics, the technology-related research (see Jaffe et al. 2003 for a review) primarily treats the problem in a deterministic setting, abstracting away from the uncertainty that firms face when choosing technologies and investing in capacity, with firms selecting a single technology (i.e., cost curve) as a consequence. Requate (1998) explores technology choice under emissions regulation in a deterministic competitive setting, with an innovating firm selecting a technology from a continuum of options while competing firms each operate a common legacy technology. Requate and Unold (2003), and Requate (2005) also treat the problem deterministically in a competitive setting where each firm selects a single technology. Zhao (2003) and Krysiak (2008) treat technology choice under emissions regulation in a competitive and dynamic setting. In both papers, firms selects a single technology from a continuum of infinite options rather than selecting a portfolio from among discrete choices. Further, Requate (1998), Requate and Unold (2003), and Zhao (2003) do not include capacity and output as firm decisions, and Requate (2005) abstracts away from capacity investment costs, which are central in the capital-intensive sectors under emissions regulation today. Chen and Tseng (2011) models the difference in clean technology (natural 
gas) adoption under cap-and-trade and carbon tax regimes, finding that a cap-and-trade regime incentivizes earlier adoption. However, Chen and Tseng (2011) does not study the firms technology choice, capacity size, or production decisions, assuming that the firm: begins with a fixed amount of coal-fired power generation capacity; can add a fixed amount of natural gas capacity (with the timing of the expansion decided by the firm); and utilizes all of its capacity.

\section{Capacity Portfolio Decisions under Emissions Regulation}

We model emissions regulation in a setting where the firm commits to a capacity portfolio under demand uncertainty, but produces after this uncertainty has resolved. This reflects the serve-toorder environment faced by power generators (responsible for $70 \%$ of Europe's regulated emissions), and the environment in capital-intensive, mature industries where the primary drivers of uncertainty are economic and fairly well-known in the short-run. In the cap-and-trade setting, the firm also faces an uncertain emissions price when making investment decisions, while they know the tax rate ex ante in the emissions tax setting.

\subsection{Capacity portfolio under emissions tax}

To address the technology choice problem under an emissions tax, we employ a two-stage model. During the first (investment) stage, the firm builds its capacity portfolio from two technology types $i \in N=\{1,2\}$, with each type defining fixed investment cost per unit of capacity, fixed operating and maintenance $(\mathrm{O} \& \mathrm{M})$ cost, variable operating cost, and emissions intensity parameters, $\beta_{i} \geq 0$, $\gamma_{i} \geq 0, b_{i} \geq 0$, and $\alpha_{i} \geq 0$, respectively. Without loss of generality, we assume technology 1 is "dirty" and technology 2 is "clean", i.e., $\alpha_{1} \geq \alpha_{2}$. In this stage, the firm chooses capacities $K_{i}$ to maximize expected profit, incurring investment cost $K_{i} \beta_{i}, \forall i$. The chosen capacities $K_{1}$ and $K_{2}$ constrain the firm's second stage production decision. The total capacity investment $\operatorname{cost} K_{1} \beta_{1}+K_{2} \beta_{2}$ is fixed (and sunk in stage two) as it is unaffected by the firm's second stage production decisions.

Between stage one and stage two, stochastic demand $\tilde{D}$ is realized. In the second (production) stage, the firm serves realized demand $d$ by choosing non-negative production quantities $q_{i} \leq K_{i}$. The firm collects price $p(\tau)$, incurs unit production cost $b_{i}+\alpha_{i} \tau$ for every unit sold where $\tau \geq 0$ is the emissions tax rate, and pays fixed O\&M $\operatorname{cost} \gamma_{i}$ for each unit of capacity that it owns. For each unit of unmet demand, the firm incurs penalty $r \geq 0$, which represents any formal financial repercussions or loss of goodwill.

In order to explicitly characterize capacities, discrete technology choice papers with uncertain demand generally make one of three assumptions to determine price. They assume: i) 100\% utilization of capacity (i.e., Goyal and Netessine 2007); ii) a monopolistic firm (i.e., Bish and Wang 2004, Goyal and Netessine 2011, and Boyabatli and Toktay 2011) in which case 100\% utilization results; or iii) a fixed and exogenous market price (e.g., Fine and Freund 1990, Harrison and 
Van Mieghem 1999, Netessine et al. 2002, Tomlin and Wang 2005, and Wang et al. 2013). These assumptions do not fit the emission regulated capacity investment setting where utilization can often run considerably below $100 \%$ and price in some sectors is expected to increase as a result of emissions regulation; e.g., utilization in European Cement was less than 60\% in 2010 (Boston Consulting Group 2012), and price is projected to increase by up to $30 \%$ in US power generation as a result of emissions regulation (İşlegen and Reichelstein 2011). Therefore, we allow price to vary with the variable cost (including the emissions cost) of the technology that the firm would choose to dispatch last. Price $p(\tau)$ is determined by baseline price $p^{B}$ and the pass through of a portion $\omega \in[0,1) \times 100 \%$ of the lower dispatch priority variable cost so that $p(\tau)=p^{B}+\max _{i}\left(b_{i}+\alpha_{i} \tau\right) \omega$. In order to preserve tractability, we assume that demand is perfectly inelastic to these changes in price. While imperfect, this assumption reasonably reflects the context in three emissions regulated sectors of principal interest: power generation, steel, and cement.

Power generation. The price elasticity of demand for electricity is estimated at -0.32 (Bernstein and Griffin 2005). At an emissions allowance price of $\$ 15 /$ ton of $\mathrm{CO}_{2},{ }^{1}$ the US Energy Information Administration (2008) projects that electricity prices would increase by $8 \%$. İşlegen and Reichelstein (2011) estimate an upper bound on retail electricity price increases of $30 \%$ at emissions prices over $\$ 70 /$ ton of $\mathrm{CO}_{2}$. This implies that increases in electricity prices resulting from emissions regulation would decrease electricity demand from just $2.5 \%$ in expectation to a maximum of $9.6 \%$ (with the maximum based on the upper bound price increase estimated by İşlegen and Reichelstein 2011).

Steel. The price elasticity of demand for steel is estimated to be -0.30 (Mathiesen and Moestad 2004). At an emissions price of $\$ 20 /$ ton of $\mathrm{CO}_{2}$, basic oxygen furnace (BOF) processes are projected to experience a $20 \%$ to $30 \%$ increase in production cost (Mathiesen and Moestad 2004). ${ }^{2}$ McKinsey and Company (2006) estimates that only $6 \%$ of these costs would be passed through to price due to the global nature of competition in the BOF sub-sector (i.e., there are mills located in regions that are not emissions regulated, essentially acting as a competitive fringe that limits the ability of emissions-regulated firms to increase price). This projects to a total decrease in demand as a result of cost pass-through of no more than one-half of one percent.

Cement. The price elasticity of demand for cement is estimated at -0.27 in Denmark (La Cour and Mollgaard 2002) and at -0.16 in the US (Miller and Osborne 2010). Ponssard and Walker (2008) estimate production cost increases in the EU cement sector of $52 \%$ and $140 \%$ at emissions prices of 20 and 50 euros/ton of $\mathrm{CO}_{2}$, respectively. They further estimate a cost pass-through

${ }^{1} \mathrm{~A} \$ 15 /$ ton of $\mathrm{CO}_{2}$ is in line with the US Environmental Protection Agency (2009) estimated allowance price under the Waxman-Markey Bill (H.R. 2454) and the US Environmental Protection Agency (2010) estimated price under the American Power Act (S. 1733).

${ }^{2} \mathrm{BOF}$ steel production generates 1.8 tons of direct $\mathrm{CO}_{2}$ emissions per ton of steel versus the 0.05 tons of direct $\mathrm{CO}_{2}$ emissions per ton of steel produced through electric arc furnace production (McKinsey and Company 2006). 
percentage ranging from $70 \%$ to over $80 \%$ (representing market price increases of $13.8 \%$ at an emissions price of 20 euros/ton of $\mathrm{CO}_{2}$ and $32.2 \%$ at an emissions price of 50 euros/ton of $\mathrm{CO}_{2}$ ). As a consequence, Ponssard and Walker (2008) estimate demand to decrease by less than $4 \%$ at the 20 euro emissions allowance price, and less than $9 \%$ at the 50 euro emissions allowance price (or roughly $5 \%$ at most if one applies the Miller and Osborne (2010) elasticity estimate). Supporting a minimal projected demand impact, Aldy and Pizer (2013) estimate only a $0.2 \%$ decrease in net employment in the US cement sector as a result of emissions regulation at an allowance price of $\$ 15 /$ ton of $\mathrm{CO}_{2}$.

In short, based on existing literature, cost pass-through would result in minimal demand attenuation in the sectors that concern us in an emissions regulation context. While a perfect inelasticity assumption is strong, it reasonably reflects our highly inelastic focal sectors.

Second stage problem. The firm earns per unit margin $\eta_{i}(\tau)=p(\tau)+r-b_{i}-\alpha_{i} \tau$ for each unit of demand it fulfills with technology $i$. In the second stage, the firm maximizes total operating margin

$$
\begin{gathered}
\pi(\underline{K}, d, \tau)=\max _{q_{1}, q_{2}}\left(\sum_{i=1}^{2}\left(p(\tau)-b_{i}-\alpha_{i} \tau\right) q_{i}-\gamma_{i} K_{i}\right)-r\left(d-\sum_{i=1}^{2} q_{i}\right) \\
=\max _{q_{1}, q_{2}}\left(\sum_{i=1}^{2} \eta_{i}(\tau) q_{i}-\gamma_{i} K_{i}\right)-r d \\
\text { s.t. } 0 \leq q_{i} \leq K_{i}, \forall i \\
\sum_{i=1}^{2} q_{i} \leq d .
\end{gathered}
$$

Let $\xi(\tau, i)$ order technology types given emissions tax $\tau$, so that

$$
\xi(\tau, 1)=\underset{i \in N}{\operatorname{argmin}} b_{i}+\alpha_{i} \tau \quad \text { and } \quad \xi(\tau, 2)=N \backslash \xi(\tau, 1) .
$$

Let $\underline{K}(\tau)$ represent the vector of capacities for a given $\tau$, ordered in terms of increasing production costs through $\xi(\tau, i)$, i.e., $\underline{K}(\tau)=\left(K_{\xi(\tau, 1)}, K_{\xi(\tau, 2)}\right)$, where $b_{\xi(\tau, 1)}+\alpha_{\xi(\tau, 1)} \tau \leq b_{\xi(\tau, 2)}+\alpha_{\xi(\tau, 2)} \tau$. For brevity, we will use the notation $[i]$ for $\xi(\tau, i)$, but the reader should note that merit ordering depends on emissions price. With constant tax rate, $\tau$, there is a single possible merit order. Therefore, where $(a)^{+}=\max (0, a)$, the firm maximizes operating margin by choosing quantities

$$
q_{[1]}=\min \left\{K_{[1]}, d\right\} \quad \text { and } \quad q_{[2]}=\min \left\{K_{[2]},\left(d-K_{[1]}\right)^{+}\right\}
$$


First stage problem. To avoid trivial outcomes, we assume $\eta_{i}(\tau)-\beta_{i}-\gamma_{i}>0, \forall i$, which ensures that each technology is feasible. All proofs are provided in Appendix 1.

In the first stage of the emissions tax setting, with $\tau$ known ex ante, the firm faces uncertain demand $\tilde{D}$. Therefore, the firm maximizes expected profits by solving

$$
\begin{gathered}
\Pi(\tilde{D}, \tau)=\max _{K_{1}, K_{2}} \mathbb{E}[\pi(\underline{K}, \tilde{D}, \tau)]-\sum_{i=1}^{2} \beta_{i} K_{i} \\
\text { s.t. } K_{i} \geq 0, \forall i .
\end{gathered}
$$

Joint concavity of $\Pi(\cdot)$ in $K_{1}$ and $K_{2}$ is proven in Appendix 1. As the cross-partial is negative, the upper bound of $K_{[i]}$ in the emissions tax setting, $\bar{K}_{[i]}^{T}(\tau)$, is determined when capacity of the other type $-i$ is zero, i.e., when $K_{[-i]}=0$, so $\bar{K}_{[i]}^{T}(\tau)=F_{\tilde{D}}^{-1}\left(1-\left(\beta_{[i]}+\gamma_{[i]}\right) / \eta_{[i]}(\tau)\right)$.

Capacity decisions. Where $F_{\tilde{D}}$ represents the CDF of the demand, the following proposition summarizes the solution to the emissions tax capacity decision:

Proposition 1. Under emissions tax regulation, the optimal capacities, $K_{[1]}^{*}(\tau)$ and $K_{[2]}^{*}(\tau)$ are characterized by

$$
K_{[1]}^{*}(\tau)= \begin{cases}\bar{K}_{[1]}^{T}(\tau) & \text { if } \quad\left(\beta_{[2]}+\gamma_{[2]}\right) / \eta_{[2]}(\tau) \geq\left(\beta_{[1]}+\gamma_{[1]}\right) / \eta_{[1]}(\tau) \\ 0 & \text { if } \eta_{[1]}(\tau)-\beta_{[1]}-\gamma_{[1]} \leq \eta_{[2]}(\tau)-\beta_{[2]}-\gamma_{[2]} \\ F_{\tilde{D}}^{-1}\left(1-\frac{\beta_{[1]}+\gamma_{[1]}-\beta_{[2]}-\gamma_{[2]}}{\eta_{[1]}(\tau)-\eta_{[2]}(\tau)}\right) & \text { otherwise, }\end{cases}
$$

and

$$
K_{[2]}^{*}(\tau)= \begin{cases}0 & \text { if } \quad\left(\beta_{[2]}+\gamma_{[2]}\right) / \eta_{[2]}(\tau) \geq\left(\beta_{[1]}+\gamma_{[1]}\right) / \eta_{[1]}(\tau) \\ \bar{K}_{[2]}^{T}(\tau) & \text { if } \quad \eta_{[1]}(\tau)-\beta_{[1]}-\gamma_{[1]} \leq \eta_{[2]}(\tau)-\beta_{[2]}-\gamma_{[2]} \\ \bar{K}_{[2]}^{T}(\tau)-K_{[1]}^{*}(\tau) & \text { otherwise. }\end{cases}
$$

The firm's capacity portfolio will be composed of a single technology under either of two conditions: i) if per unit profit $\eta_{i}(\tau)-\beta_{i}-\gamma_{i}$ increases in merit order; or ii) if the return on capital per unit delivered $\eta_{i}(\tau) /\left(\beta_{i}+\gamma_{i}\right)$ decreases in merit order. Under the first condition, the per unit operating margin advantage type [1] has over type [2] is dominated by its investment cost disadvantage. Type [2] would generate more profit for each unit sold, and it would require less investment per unit of capacity. As a consequence, type [1] capacity would be excluded from the portfolio. Under the second condition, the firm requires fixed costs per dollar of operating margin that it stands to gain to decrease in merit order - i.e., it requires at least proportionately less investment risk for the lower operating margin technology. If the investment cost for technology [2], is not sufficiently less than the investment cost technology [1], then technology [2] would be be excluded from the firm's capacity portfolio. Under either condition, the firm would invest in a single-technology portfolio of capacity $\bar{K}_{[2]}^{T}(\tau)$ and $\bar{K}_{[1]}^{T}(\tau)$, respectively. By doing so, the firm positions itself to serve a portion of demand that increases in operating margin $\eta_{[i]}(\tau)$ and decreases in investment cost $\beta_{[i]}$. 
If, on the other hand, neither single-technology condition holds, then the firm invests in a capacity portfolio consisting of multiple technologies. The optimal multi-technology portfolio serves potential demand in tranches, dispatching technology [1] to serve the most certain demand and technology [2] to serve less certain demand (with demand that exceeds total capacity going unserved). By serving demand in tranches in this manner, under the conditions required for a multi-technology portfolio, the firm hedges demand risk by trading off profit margin for lower investment cost at more speculative levels of demand. This implies that the firm's total capacity is determined independent from the economics of the type preferred in merit order, evident through Proposition 1 where total capacity in mixed-technology portfolios is determined solely by $\bar{K}_{[2]}^{T}(\tau)$. This observation has environmental implications with respect to the emissions tax rate and the effect of investment and production subsidies which we discuss in detail in Section 4.2 .

\subsection{Capacity portfolio under emissions cap-and-trade}

Under a cap-and-trade regime, rather than set a price for each unit of emissions, the regulator decides on the total quantity of emissions to allow - i.e., the "cap" - by selecting how many allowances to inject into the carbon economy. Emissions price is determined as these allowances are bought and sold by firms that require them to operate in the regulated region and by those speculating on their financial value. This results in a volatile emissions price. The managers operating under the EU-ETS whom we have spoken with point to this uncertain emissions price as the most salient feature of the regime. The set-up of this model therefore resembles that of the emissions tax model above except the constant tax rate $\tau$ is replaced by a stochastic emissions price, $\tilde{e}$.

In theory, each firm's decisions impact the demand for emissions allowances, and therefore should affect emissions price. However, in practice, no firm under the EU-ETS possesses the market power to substantively impact carbon price through its own technology choice decisions.

In 2011, over 11,000 facilities owned by more than 900 firms were regulated by the EU-ETS. Based on Carbon Market Data's EU-ETS Company Database, which accounts for $92.5 \%$ of all 2011 verified emissions, the firm with the largest share of verified emissions generated just $5.6 \%$ of EUETS regulated emissions. The $98^{\text {th }}$ and $90^{\text {th }}$ percentile firms (i.e., the $18^{\text {th }}$ and $89^{\text {th }}$ largest shares of the 894 firms included in the database) generated $0.96 \%$ and $0.21 \%$ of verified emissions, respectively, and the average firm generated only $0.10 \%$. Based on this data, the Herfindahl-Hirschman Index for the EU-ETS emissions market in 2011 was 0.013. With any given firm accounting for such a small portion of emissions allowance consumption, and realizing that these allowances are also bought and sold by institutions other than those consuming them, the impact of any firm's technology choice decisions on emissions price would be negligible. Accordingly, we assume that firms in the cap-and-trade carbon economy are atomistic with respect to emissions price. 
We denote decisions and objectives in the cap-and-trade setting with hat notation. The firm chooses quantities $\hat{q}_{i}$ in stage two to maximize operating margin $\hat{\pi}$, and it chooses capacities $\hat{K}_{i}$ in the first stage to maximize expected profit $\hat{\Pi}$.

Second stage problem. In the second stage of the cap-and-trade setting, demand and emissions price uncertainty have resolved as $d$ and $e$, respectively. The firm maximizes total operating profit

$$
\begin{aligned}
\hat{\pi}\left(\hat{K}_{1}, \hat{K}_{2}, d, e\right)=\max _{\hat{q}_{1}, \hat{q}_{2}}\left(\sum_{i=1}^{2} \eta_{i}(e) \hat{q}_{i}-\gamma_{i} \hat{K}_{i}\right)-r d \\
\text { s.t. } 0 \leq \hat{q}_{i} \leq \hat{K}_{i}, \forall i \\
\sum_{i=1}^{2} \hat{q}_{i} \leq d .
\end{aligned}
$$

The decisions derived from (4) are consistent with both full auctioning (i.e., when no free allowances are issued to firms) and a regime that freely endows each firm with some allotment of allowances. To see this, let $A$ represent the number of allowances the firm is endowed with. Therefore, Ae would represent the value of the firm's endowment. Adding Ae to (4) does not impact the firm's decisions. The calculus here is clear. The logic is as follows: the firm incurs carbon cost $\alpha_{i} e$ for each unit it produces with technology $i$, regardless of whether it owns allowances. If it does not own allowances, it must purchase $\alpha_{i}$ allowances for each unit produced with technology $i$, paying $e$ for each allowance. If it does own allowances, it loses the opportunity to sell $\alpha_{i}$ allowances for each unit produced with technology $i$ (because it consumes those allowances), which costs it $\alpha_{i} e$ per unit produced in forgone income. Either way, the firm incurs (direct or opportunity) cost $\alpha_{i} e$ for each unit it produces with technology $i$.

Feasible stage two technologies, $i \in \ddot{N}$, include only types profitable to utilize in the second stage; i.e., $\ddot{N} \subseteq N$ such that $\eta(e) \geq 0 \forall i \in \ddot{N}$. With the uncertain demand and emissions price resolved, the second stage is deterministic and can be solved through merit ordering. As in the emissions tax setting, $\xi(e, i)$ orders the elements of the vector $\underline{\hat{K}}(e)$ from least to greatest operating cost, and we continue to use the notation $[i]$ for $\xi(e, i)$. This yields operating margin maximizing quantities

$$
\hat{q}_{[i]}=\left\{\begin{array}{cl}
\min \left(\hat{K}_{[i]},\left(d-\sum_{k=1}^{i-1} \hat{K}_{[k]}\right)^{+}\right) & \forall i \in \ddot{N} \\
0 & \forall i \in N \backslash \ddot{N} .
\end{array}\right.
$$

First stage problem. The first stage cap-and-trade decision is made under uncertainty, both with respect to demand and emissions cost, with the firm choosing capacities to maximize profits

$$
\begin{gathered}
\hat{\Pi}(\tilde{D}, \tilde{e})=\max _{\hat{K}_{1}, \hat{K}_{2}} \mathbb{E}_{\tilde{D}, \tilde{e}}\left[\hat{\pi}\left(\hat{K}_{1}, \hat{K}_{2}, \tilde{D}, \tilde{e}\right)\right]-\sum_{i=1}^{2} \beta_{i} \hat{K}_{i} \\
\text { s.t. } \hat{K}_{i} \geq 0, \forall i .
\end{gathered}
$$


To avoid either type being trivially excluded from the firm's optimal capacity portfolio due to being unprofitable in expectation, we assume $\mathbb{E}_{\tilde{e}}\left[\eta_{i}(\tilde{e})\right]-\beta_{i}-\gamma_{i}>0$, for both types.

Since production cost is uncertain given the stochastic emissions price, merit order is also uncertain in the first stage. Therefore, we partition the support of $\tilde{e}$ into merit order intervals $\tilde{e}_{j}$, where $\tilde{e}_{j}$ represents the interval over $\tilde{e}$ where the $j$ th merit ordering holds, $j \in \Theta=\{1, \ldots, \theta\}$. The boundaries of each interval $\tilde{e}_{j}$ are determined in three ways: by the lower and upper limit of the support for $\tilde{e}$ (defining the lower bound of interval $j=1$ and the upper bound of $j=\theta$ ), by changes in merit order (i.e., the production cost crossing point for two types), and by changes in the membership of $\ddot{N}$ (i.e., where a type's production cost crosses the threshold $p+r$ ).

Define $\tilde{e}_{1}$ as the merit order interval over $\tilde{e}$ where type 1 capacity is preferred and define $\tilde{e}_{2}$ as the interval where type 2 capacity is preferred. Further, define $\tilde{e}_{3}$ as the merit order interval where one type is unprofitable to operate, with $\tilde{e}_{3, i}$ noting type $i$ as the profitable type (i.e., $\ddot{N}=\{i\}$ for all $\left.e \in \tilde{e}_{3, i}\right)$. Finally, define $\tilde{e}_{4}$ as the interval where neither type is profitable to operate. If type $i$ is dominated in merit order over the support of $\tilde{e}$, then $\tilde{e}_{i}$ and $\tilde{e}_{3, i}$ are empty.

Concavity is proven in Appendix 1. The cross-partial is non-positive. As a consequence, the upper bound of $\hat{K}_{i}$, defined here as $\bar{K}_{i}^{C}$, is determined when $\hat{K}_{-i}=0$. Therefore, where $\bar{\eta}_{i}\left(\tilde{e}_{j}\right)$ is the weighted average operating margin per unit produced with technology $i$ over the emissions price interval $\tilde{e}_{j}$, and $\bar{K}_{i}^{C}(\tilde{e})=F_{\tilde{D}}^{-1}\left(1-\left(\beta_{i}+\gamma_{i}\right) /\left[\bar{\eta}_{i}\left(\tilde{e}_{i}\right)+\bar{\eta}_{i}\left(\tilde{e}_{-i}\right)+\bar{\eta}_{i}\left(\tilde{e}_{3, i}\right)\right]\right)$.

3.2.1. Cap-and-trade with a dominant second stage technology Here we address the setting where one technology dominates merit ordering over the support of $\tilde{e}$ - i.e., there exists a technology type $i$ where $\operatorname{Pr}\left(\eta_{i}(\tilde{e}) \geq \eta_{-i}(\tilde{e})\right)=1$.

Capacity decisions. We summarize the solution to the cap-and-trade setting when a type $i$ dominates the merit order with the following proposition:

Proposition 2. Assume cap-and-trade regulation where type $i$ dominates merit order, i.e., $\operatorname{Pr}\left(\eta_{i}(\tilde{e}) \geq \eta_{-i}(\tilde{e})\right)=1$, then the vector of optimal capacities, $\underline{K}^{*}$ is characterized by

$$
\hat{K}_{i}^{*}(\tilde{e})= \begin{cases}\bar{K}_{i}^{C}(\tilde{e}) & \text { if } \quad\left(\beta_{-i}+\gamma_{-i}\right) / \bar{\eta}_{-i}\left(\tilde{e}_{i}\right) \geq\left(\beta_{i}+\gamma_{i}\right) /\left[\bar{\eta}_{i}\left(\tilde{e}_{i}\right)+\bar{\eta}_{i}\left(\tilde{e}_{3, i}\right)\right] \\ 0 & \text { if } \quad \bar{\eta}_{-i}\left(\tilde{e}_{i}\right)-\beta_{-i}-\gamma_{-i} \geq \bar{\eta}_{i}\left(\tilde{e}_{i}\right)+\bar{\eta}_{i}\left(\tilde{e}_{3, i}\right)-\beta_{i}-\gamma_{i} \\ F_{\tilde{D}}^{-1}\left(1-\frac{\beta_{i}+\gamma_{i}-\beta_{-i}-\gamma_{-i}}{\bar{\eta}_{i}\left(\tilde{e}_{i}\right)+\bar{\eta}_{i}\left(\tilde{e}_{3, i}\right)-\bar{\eta}_{-i}\left(\tilde{e}_{i}\right)}\right) & \text { otherwise, }\end{cases}
$$

and

$$
\hat{K}_{-i}^{*}(\tilde{e})=\left\{\begin{array}{lll}
0 & \text { if } \quad\left(\beta_{-i}+\gamma_{-i}\right) / \bar{\eta}_{-i}\left(\tilde{e}_{i}\right) \geq\left(\beta_{i}+\gamma_{i}\right) /\left[\bar{\eta}_{i}\left(\tilde{e}_{i}\right)+\bar{\eta}_{i}\left(\tilde{e}_{3, i}\right)\right] \\
\bar{K}_{-i}^{C}(\tilde{e}) & \text { if } \quad \bar{\eta}_{-i}\left(\tilde{e}_{i}\right)-\beta_{-i}-\gamma_{-i} \geq \bar{\eta}_{i}\left(\tilde{e}_{i}\right)+\bar{\eta}_{i}\left(\tilde{e}_{3, i}\right)-\beta_{i}-\gamma_{i} \\
F_{\tilde{D}}^{-1}\left(1-\frac{\beta_{-i}+\gamma_{-i}}{\bar{\eta}_{-i}\left(\tilde{e}_{i}\right)}\right)-\hat{K}_{i}^{*}(\tilde{e}) & \text { otherwise. }
\end{array}\right.
$$


Note that $\hat{K}_{i}^{*}(\tilde{e})$ mirrors the solution for type [1] technology under an emissions tax setting in Proposition 1, except that operating margins in the cap-and-trade setting are expectations based on the uncertainty of $\tilde{e}$. Similarly, the solution for $\hat{K}_{-i}^{*}(\tilde{e})$ mirrors that of the merit order dominated type in Proposition 1. As in the tax setting, the firm would opt to include a type dominated in merit order within their capacity portfolio if its per unit investment cost were sufficiently low to offset its operating margin disadvantage (i.e., if the first condition for $\hat{K}_{-i}^{*}(\tilde{e})$ does not hold).

3.2.2. Cap-and-trade with no dominant second stage technology Here we address the setting without a merit-order-dominant technology. In such a setting, there exists both an emissions price interval in which type 1 is merit-order-preferred, and an interval in which type 2 is merit-order-preferred; i.e., for all $i$, there exists an $e$ in the support of $\tilde{e}$ such that $\eta_{i}(e) \geq \eta_{-i}(e)$.

Capacity decisions. Capacity solutions in the cap-and-trade setting where no type dominates are symmetric for $\hat{K}_{1}$ and $\hat{K}_{2}$ and are characterized by the following proposition,

Proposition 3. Under cap-and-trade regulation where neither type dominates merit order, the optimal vector of capacities is characterized by

$$
\hat{K}_{i}^{*}\left(\hat{K}_{-i}, \tilde{e}\right)=\left\{\begin{array}{l}
0 \quad \text { if } \quad \mathbb{E}_{\tilde{e}}\left[\eta_{i}(\tilde{e})\right]-\beta_{i}-\gamma_{i} \leq F_{\tilde{D}}\left(\bar{K}_{-i}^{C}(\tilde{e})\right)\left(\bar{\eta}_{i}\left(\tilde{e}_{-i}\right)-\bar{\eta}_{-i}\left(\tilde{e}_{i}\right)\right) \\
\bar{K}_{i}^{C}(\tilde{e}) \quad \text { if } \quad \mathbb{E}_{\tilde{e}}\left[\eta_{-i}(\tilde{e})\right]-\beta_{-i}-\gamma_{-i} \leq F_{\tilde{D}}\left(\bar{K}_{i}^{C}(\tilde{e})\right)\left(\bar{\eta}_{-i}\left(\tilde{e}_{i}\right)-\bar{\eta}_{i}\left(\tilde{e}_{-i}\right)\right) \\
F_{\tilde{D}}^{-1}\left[\left(1-\frac{\beta_{i}+\gamma_{i}-\beta-i}{\bar{\eta}_{i}\left(\tilde{e}_{i}\right)+\bar{\eta}_{i}\left(\tilde{e}_{3, i}\right)-\bar{\eta}_{-i}\left(\tilde{e}_{i}\right)}\right)-\left(1-F_{\tilde{D}}\left(\hat{K}_{-i}\right)\right) \frac{\bar{\eta}_{-i}\left(\tilde{e}_{-i}\right)+\bar{\eta}_{-i}\left(\tilde{e}_{3,-i}\right)-\bar{\eta}_{i}\left(\tilde{e}_{-i}\right)}{\bar{\eta}_{i}\left(\tilde{e}_{i}\right)+\bar{\eta}_{i}\left(\tilde{e}_{\tilde{s}, i}\right)-\bar{\eta}_{-i}\left(\tilde{e}_{i}\right)}\right] \quad \text { otherwise. }
\end{array}\right.
$$

In the interior solution, the term in the left hand parentheses is identical to the interior solution for type [1] technology in Proposition 2. The second term of the interior solution is always positive and decreases in the capacity of the other type, $\hat{K}_{-i}$. The interior solution for the dominant merit order type in Proposition 2 therefore provides the upper bound for interior solutions in the mixed merit order setting. The ratio of the last term of the interior solution increases (decreases) with the expected per unit operating margin advantage of type $-i$ (type $i$ ) over emissions price intervals in which it is preferred in merit order. As such, this ratio can be thought of as a substitution effect; a relatively greater expected operating margin for type $-i$ capacity leads to a relatively smaller investment in type $i$ capacity.

Using the symmetric reaction curves $\hat{K}_{i}^{*}\left(\hat{K}_{-i}, \tilde{e}\right)$ defined in Proposition 3, numerical solutions can be obtained through an iterative procedure that converges globally to the optimal solution under the following strict concavity (SC) condition: $f_{\tilde{D}}(x)>0, \quad \forall x \in\left[0, \max \left\{\bar{K}_{1}^{C}(\tilde{e}), \bar{K}_{2}^{C}(\tilde{e})\right\}\right]$, where $f_{\tilde{D}}(\cdot)$ is the probability density of demand.

Proposition 4. Assume $S C .^{3}$ Given any feasible solution $\hat{K}_{i}^{0}$ and $\hat{K}_{-i}^{0}$, the sequence $\underline{K}^{t}$ defined by $\hat{K}_{i}^{t+1}=\hat{K}_{i}^{*}\left(\hat{K}_{-i}^{t}\right)$ and $\hat{K}_{-i}^{t+1}=\hat{K}_{-i}^{*}\left(\hat{K}_{i}^{t}\right), t=\{0,1,2, \ldots\}$ converges to $\hat{K}_{i}^{*}\left(\hat{K}_{-i}, \tilde{e}\right)$ and $\hat{K}_{-i}^{*}\left(\hat{K}_{i}, \tilde{e}\right)$.

${ }^{3}$ In settings where SC does not hold, Proposition 4 can still be used to solve the original problem by subtracting $\epsilon\left(\hat{K}_{1}^{2}+\hat{K}_{2}^{2}\right), \epsilon>0$ from the objective function given by (6). As explained in Appendix 1, this gives rise to a strictly concave objective function whose solution converges to the solution of (6) as $\epsilon \rightarrow 0$. 


\section{Implications of Portfolio and Production Decisions}

In the previous section, we characterized the firm's optimal capacity portfolio under an emissions tax and a cap-and-trade regime (Sections 3.1 and 3.2, respectively). Here, we explore the implications of those portfolio decisions.

\subsection{Managerial Implications}

Proponents of an emissions tax regime posit that emissions price uncertainty under cap-and-trade renders a tax more attractive for firms (e.g., Metcalf 2009; Parry and Pizer 2007), arguing that emissions prices that fluctuate on "a daily (or perhaps hourly) basis" can erode firm value (Metcalf 2009). Proposition 5 contributes a counterargument to this debate. It indicates that firms would earn greater expected profit under cap-and-trade precisely because of the regime's emissions price uncertainty. Define $\mu_{e}$ as the mean emissions price under cap-and-trade.

Proposition 5. If $\tau=\mu_{e}$, then emissions price uncertainty under cap-and-trade results in greater expected profit than a constant rate under an emissions tax; i.e., $\hat{\Pi}(\tilde{D}, \tilde{e}) \geq \Pi(\tilde{D}, \tau)$.

This result follows from Jensen's inequality. Compare the profits of two firms. Firm A that faces a constant emissions price and operates the optimal carbon tax portfolio $K_{1}^{*}(\tau)$ and $K_{2}^{*}(\tau)$, and firm B that faces an uncertain emissions price, but also operates the optimal carbon tax portfolio. Because expected profit is piecewise convex in emissions price for a given capacity portfolio, in expectation, the firm B facing emissions price uncertainty earns profit at least as great as firm A that faces a constant emissions price, despite firm B's capacity portfolio being optimized for a constant emissions price. If firm B were to optimize their capacity portfolio for the emissions price uncertainty that they face (i.e., selecting capacities $\hat{K}_{1}^{*}$ and $\hat{K}_{2}^{*}$ ) it would earn expected profits at least as great as those earned by operating the optimal carbon tax portfolio under an uncertain emissions price. It follows that expected profit under cap-and-trade $\hat{\Pi}(\tilde{D}, \tilde{e})$ is at least as great as expected profit under an emissions tax $\Pi(\tilde{D}, \tau)$ when $\tau=\mu_{e}$.

While Jensen's inequality provides the mathematical explanation for this result, it is useful to explore the operational drivers that contribute to it. Corollaries 1 and 2 identify the option not to operate and dispatch flexibility as two such drivers.

COROLlary 1. The option not to operate contributes to cap-and-trade expected profit advantage over emissions tax iff $\exists i \mid \operatorname{Pr}\left(\tilde{e}>\frac{p^{B}+r+\omega b_{[2]}-b_{i}}{\alpha_{i}-\omega \alpha_{[2]}}\right)>0, \alpha_{i}-\omega \alpha_{[2]}>0, \hat{K}_{i}^{*}(\tilde{e})>0$, and $\operatorname{Pr}(\tilde{D}>$ $\left.\hat{K}_{-i}^{*}(\tilde{e})\right)>0$ if $\xi(e, i)=[2]$.

Emissions price uncertainty creates value for a firm under cap-and-trade through an option not to operate under two conditions: i) there is a non-zero probability that $\tilde{e}$ resolves such that a technology type in the firm's portfolio is unprofitable to operate with respect to operating margin 
$p(\tau)+r-b_{i}-\alpha_{i} e ;^{4}$ and ii) there is a non-zero probability that demand exceeds the firm's capacity of the alternative type if that alternative technology is favored in merit order. By choosing to exercise its option not to operate, the firm avoids worst-case emissions price outcomes. By doing so, the firm effectively right-censors the emissions prices that it is exposed to, thereby increasing expected profit. Figure 1 illustrates this effect in a setting where the portfolio consists of a single technology type and emissions price follows a two-point emissions price distribution.

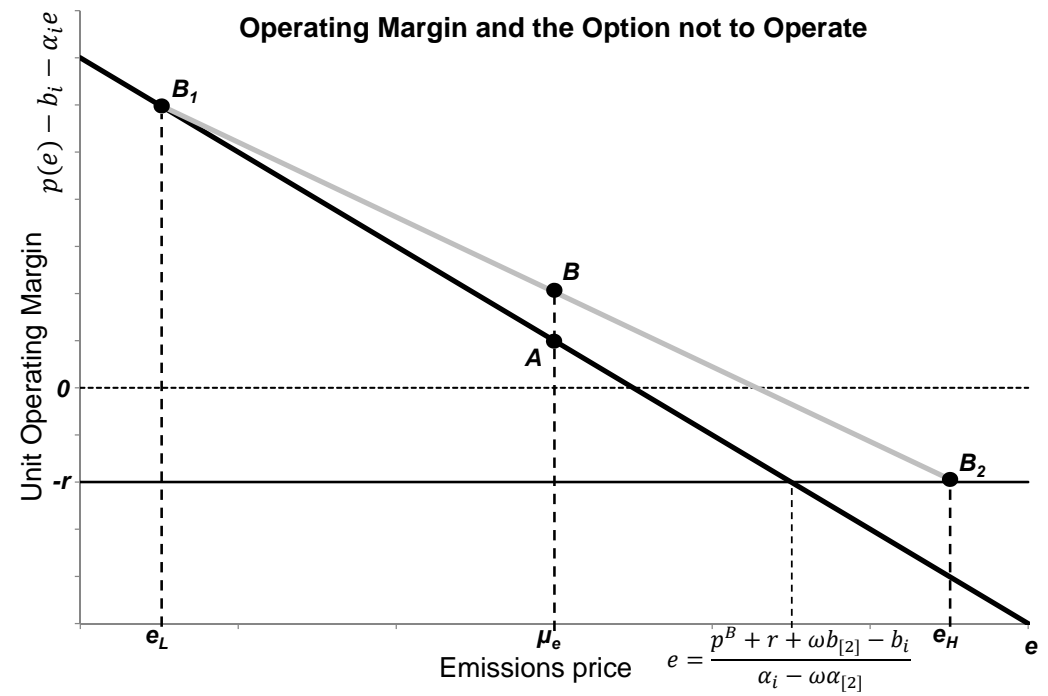

Figure 1 The option not to operate conditionally results in a greater per unit expected operating margin with emissions price volatility (point B) than with a constant emissions price (point A).

In Figure 1, the bold black line represents the margin earned by the firm for each unit of demand they fulfill, i.e., $p(\tau)-b_{i}-\alpha_{i}$ e. Point A represents the unit operating margin earned in the emissions tax setting, and point $\mathrm{B}_{1}$ represents the unit operating margin under cap-and-trade when the low emissions price $e_{L}$ is realized. However, the firm would choose not to operate if the per unit operating margin is less than the penalty that they would incur for leaving demand unserved: i.e., if $p(\tau)-b_{i}-\alpha_{i} e<-r$ or, equivalently, if $e>\left(p^{B}+r+\omega b_{[2]}-b_{i}\right) /\left(\alpha_{i}-\omega \alpha_{[2]}\right)$. At $e_{H}$, the firm would not operate, choosing instead to incur the per unit penalty $-r$, represented by point $\mathrm{B}_{2}$. In expectation, the firm under cap-and-trade earns per unit operating profit $\mathrm{B}$, which is greater than the operating profit earned under a carbon tax because $\operatorname{Pr}\left(\tilde{e}>\left(p^{B}+r+\omega b_{[2]}-b_{i}\right) /\left(\alpha_{i}-\omega \alpha_{[2]}\right)\right)>0$

\footnotetext{
${ }^{4}$ The emissions price threshold $\tilde{e}>X_{i}$, where $X_{i}=\left(p^{B}+r+\omega b_{[2]}-b_{i}\right) /\left(\alpha_{i}-\omega \alpha_{[2]}\right)$ in Corollary 1 , is based on the assumption that the firm would idle (i.e., that per unit exit costs exceed $\gamma_{i}$ ). There may be settings in practice where such an assumption is invalid. In such settings, assuming the other conditions of Corollary 1 were met, the option to not operate would persist, but the emissions price $X_{i}$ at which the firm would exercise that option would decrease by $x_{i} \in\left[-\gamma_{i} /\left(\alpha_{i}-\omega \alpha_{[2]}\right), 0\right]$ and could be more precisely defined through a detailed, multi-period model. If exiting/re-entry were costless, then the threshold $X_{i}$ would decrease by $-\gamma_{i} /\left(\alpha_{i}-\omega \alpha_{[2]}\right)$ due to potential to avoid fixed O\&M costs (i.e., the firm would choose to exit if $\left.\eta_{i}(e)<\gamma_{i}\right)$. If per unit exit costs exceeded $\gamma_{i}$, then the threshold $X_{i}$ would not change from that specified in Corollary 1 as idling would dominate exiting in the firm's choice set.
} 
for a technology in its portfolio. The example extends to the case where the firm's portfolio includes multiple technologies if there is a chance that demand will exceed capacity of a preferred and profitable technology. Therefore, whenever the conditions of Corollary 1 hold, a firm under capand-trade earns greater expected profit than a firm under a carbon tax due to the option not to operate, even with the optimal carbon tax capacity portfolio. It follows that, when these conditions hold, expected profit is greater under cap-and-trade than a carbon tax due (at least in part) to the option to not to operate.

In settings where $\omega$ is greater (i.e., where the firm can pass through a greater portion of its emissions-related costs such as deregulated power generation), the emissions price threshold at which the firm would exercise its option not to operate is commensurately greater as well. Conversely, in settings where the firm's ability to pass emissions costs through to price is less (e.g., in BOF steel and some settings in cement), the emissions allowance "strike price" for the option is less. In short, through the condition $\operatorname{Pr}\left(\tilde{e}>\left(p^{B}+r+\omega b_{[2]}-b_{i}\right) /\left(\alpha_{i}-\omega \alpha_{[2]}\right)\right)>0$, firms in high $\omega$ settings are less likely to exercise the option than firms in low $\omega$ settings. The European cement industry provides one example of a low $\omega$ setting where the option to not operate is projected to come into play, ${ }^{5}$ with Boston Consulting Group (2008) having conducted a study to identify the emissions allowance strike price at which firms would idle capacity throughout Europe.

COROllary 2. Dispatch flexibility contributes to cap-and-trade expected profit advantage over emissions tax iff $\hat{K}_{1}>0, \hat{K}_{2}>0, \operatorname{Pr}\left(\tilde{D}<\hat{K}_{1}+\hat{K}_{2}\right)>0$, and $\operatorname{Pr}\left(\tilde{e}>\left(b_{i}-b_{-i}\right) /\left(\alpha_{-i}-\alpha_{i}\right)\right) \in(0,1)$.

Expected profit increases due to dispatch flexibility — the firm's ability to choose what capacity to deploy and what capacity to hold in reserve - if three conditions are met: i) the firm's capacity portfolio consists of both technology types; ii) expected utilization is less than $100 \%$-i.e., there is a non-zero probability that total capacity exceeds demand; and iii) each type is preferred in merit order at some emissions price over the support of $\tilde{e}$. Dispatch flexibility is valuable to the firm in the cap-and-trade setting, where $\tilde{e}$ is uncertain, if each of these conditions is met. Dispatch flexibility adds no value in an emissions tax setting where $\tau$ is constant and known because, at a minimum, the last of these three conditions would not hold. ${ }^{6}$ Figure 2 illustrates this effect.

The bold gray line in Figure 2 represents the operating margin generated for each unit of technology type 1 used to fulfill demand, and the bold black line represents the operating margin generated for each unit of technology type 2 used to fulfill demand. In the tax setting (where $\tau=\mu_{e}$ ), the

\footnotetext{
${ }^{5}$ The ability to pass emissions costs through to price in European cement is limited by the threat of entry from offshore producers that do not face emissions regulation. Coastal regions are more limited in this regard than inland regions (due to the significant transport costs incurred when shipping cement).

${ }^{6}$ Although the firm conditionally invests in a portfolio including multiple technologies in an emissions tax setting, they do so as a hedge against demand uncertainty rather than a hedge against emissions price uncertainty.
} 


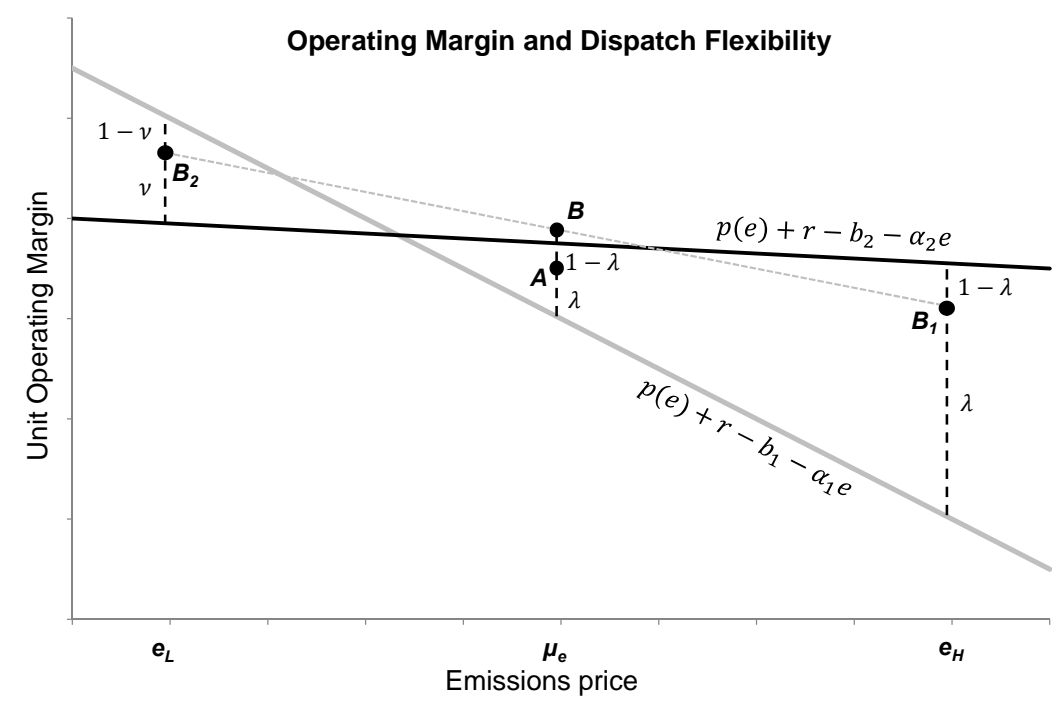

Figure 2 Expected operating margin under emissions price volatility (point B) is conditionally greater than expected operating margin under a constant emissions price (point $A$ ) due to the ability to choose dispatch order. When expected utilization is less than $100 \%, \nu>1-\lambda$ and, equivalently, $\lambda>1-\nu$.

average operating margin earned by the firm will be a convex combination of the per unit operating margin the firm earns with technology type 1 and with technology type 2 at emissions price $\mu_{e}$. In this example, type 2 is preferred in merit order at $\mu_{e}$. Therefore the firm dispatches its type 2 capacity first, fulfilling only residual demand with type 1 capacity, with $\lambda \in[0,1]$ representing the expected portion of demand fulfilled by type 2 capacity when it is preferred in merit order. The firm, therefore, earns an average operating margin of A per unit of demand that it serves. Given that type 2 is also preferred at emissions price $e_{H}$, a firm with the identical portfolio as in the tax setting would also expect to utilize technology type 2 to serve $\lambda \times 100 \%$ of demand fulfilled, earning average operating margin $\mathrm{B}_{1}$ per unit (a convex combination of the operating margin earned by deploying technology type 1 and technology type 2 at emissions price $e_{H}$ ).

At emissions price $e_{L}$, technology type 1 is preferred in merit order. Therefore, the firm would first dispatch it to serve demand, deploying technology type 2 only to serve the portion of demand that exceeded type 1 capacity. In the figure, $\nu \in[0,1]$ is the expected portion of demand fulfilled by type 1 capacity when it is preferred in merit order. Therefore, at emissions price $e_{L}$, the firm earns an average operating margin represented by point $B_{2}$ for each unit of demand that it serves. With less than $100 \%$ utilization in expectation, it follows that $\nu>1-\lambda$ and, equivalently, $\lambda>1-\nu$; i.e., the expected portion of demand fulfilled by type $i$ capacity is greater when it is favored in merit order than when it is not favored in merit order. As a consequence, the expected per unit operating margin earned when facing an uncertain emissions price, represented by point B on line segment $B_{1} B_{2}$, is greater than the expected per unit operating margin earned when facing a certain emissions price, represented by point A. 


\subsection{Policy implications}

Emissions regulation is intended to help abate global climate change by incentivizing emissions intensity reductions. One way to achieve that end is through firms' capacity portfolios, by facilitating greater adoption of clean technologies. In this section, we explore the effect that policy levers commonly used under emissions regulation have on clean technology adoption.

4.2.1. Impact of emissions price level. Increases in emissions price decrease the profitability of both clean and dirty technologies, with the rate of decrease moderated by their respective emissions intensities. As a consequence, investment in both technologies decreases as a first order effect of emissions price increases. Such regulation promotes clean technology adoption through second order effects if the clean technology is favored in merit order, or if it provides a sufficiently large emissions intensity advantage.

COROllary 3. Assume an interior solution under an emissions tax regime. Then

a) Optimal dirty capacity, $K_{1}^{*}(\tau)$, decreases in tax rate, $\tau$.

b) When not preferred in merit order, optimal clean capacity

$$
K_{2}^{*}(\tau) \begin{cases}\text { increases in } \tau \text { if } & \frac{\alpha_{1}-\alpha_{2}}{(1-\omega) \alpha_{2}}>\frac{f_{\tilde{D}}\left(1-\frac{\beta_{1}+\gamma_{1}-\beta_{2}-\gamma_{2}}{\eta_{1}(\tau)-\eta_{2}(\tau)}\right)}{f_{\tilde{D}}\left(1-\frac{\beta_{2}+\gamma_{2}}{\eta_{2}(\tau)}\right)} \frac{\beta_{2}+\gamma_{2}}{\beta_{1}+\gamma_{1}-\beta_{2}-\gamma_{2}} \frac{\left(\eta_{1}(\tau)-\eta_{2}(\tau)\right)^{2}}{\left(\eta_{2}(\tau)\right)^{2}} \\ \text { decreases in } \tau & \text { otherwise. }\end{cases}
$$

c) Optimal clean capacity, $K_{2}^{*}(\tau)$, increases in $\tau$ when it is preferred in merit order.

The effect on type 1 capacity is clear. The added cost incurred by type 1 production due to the increase in emissions tax reduces expected marginal profit, which in turn leads the firm to invest in less type 1 capacity. The first order effect on type 2 capacity is likewise clear - also a decrease as a consequence of lower expected marginal profit. However, in the case of type 2 capacity, a second order effect works in the opposite direction. The decreased investment in type 1 capacity (the preferred technology in the conditional result in Corollary 3b) leaves a greater portion of potential demand unserved by technology type 1, thereby increasing the expected marginal revenue (and profit) for technology type 2 . The LHS of the condition in Corollary $3 \mathrm{~b}$ where $K_{2}^{*}(\tau)$ increases in $\tau$ stipulates a percent difference in emissions intensity between types. If this difference is greater than the characterized threshold, the second order effect dominates and type 2 capacity increases in tax rate. When clean technology is preferred in merit order and the solution is interior (as in Corollary 3c), this second order effect always dominates.

Under a boundary solution, the technology that monopolizes the portfolio decreases in $\tau$. This indicates that $K_{2}^{*}(\tau)$ can be non-monotonic in $\tau$ : conditionally increasing in $\tau$ in a mixed portfolio, and decreasing if $\tau$ becomes sufficiently great that clean technology monopolizes the portfolio. Krass et al. (2013) find a non-monotonic effect of tax rate on clean technology adoption as well, 
but their result is quite different from that above. The Krass et al. result pertains to the adoption of a single technology only, rather than a potential portfolio of technologies, and is a consequence of demand decreasing in response to emissions costs driving an increase in price. Corollary 3 , on the other hand, follows directly from the potential for a mixed portfolio, with an interior solution (i.e., a mixed technology portfolio) as a necessary condition for $K_{2}^{*}(\tau)$ to increase in $\tau$.

4.2.2. Impact of production and investment subsidies. Subsidies are commonly used to promote investment in, and use of, clean technologies. Federally, the US subsidizes both clean technology investment and production - e.g., the Business Energy Investment Tax Credit and the Renewable Electricity Production Tax Credit, respectively. Most US states also offer clean investment and production subsidies - e.g., there are hundreds of US state-level corporate tax and rebate incentives for renewable energy alone (Database of State Incentives for Renewables \& Efficiency 2014). In Europe, several dozen such production and investment subsidies are in force in sectors where the EU-ETS also applies - e.g., see International Energy Agency (2014). Corollary 4 stipulates the conditions under which a per unit production or investment subsidy $\delta>0$ expands the firm's optimal capacity portfolio.

COROllary 4. Assume a per unit clean technology subsidy, $\delta$. If $K_{i}^{*}(\tau)>0 \forall i$ and $\eta_{2}(\tau)>\eta_{1}(\tau)$, then $K_{1}^{*}(\tau)+K_{2}^{*}(\tau)$ does not change wrt $\delta$. Otherwise, $K_{1}^{*}(\tau)+K_{2}^{*}(\tau)$ increases in $\delta$.

It should be noted that, in portfolios consisting of multiple technologies, a clean technology subsidy increases the optimal clean technology share, $\psi_{2}=K_{2}^{*}(\tau) /\left(K_{1}^{*}(\tau)+K_{2}^{*}(\tau)\right)$. However, by Corollary 4 , a clean technology subsidy only increases the firm's total capacity $K_{1}^{*}(\tau)+K_{2}^{*}(\tau)$ in mixed portfolios if the dirty technology is preferred in merit order. Figure 3 illustrates these effects.

Region $\Gamma_{[1]}$ in the figure represents expected demand served by merit-order-preferred $K_{[1]}^{*}(\tau)$ capacity, $\Gamma_{[2]}$ represents expected demand served by $K_{[2]}^{*}(\tau)$ capacity, and $\Gamma_{0}$ represents demand expected to go unserved by the firm. A subsidy targeting the merit-order preferred technology in a mixed portfolio $\left(\delta_{[1]}\right.$ in Figure 3$)$ incentivizes a substitution effect only, increasing $K_{[1]}^{*}(\tau)$ and decreasing $K_{[2]}^{*}(\tau)$, while leaving total capacity $K_{[1]}^{*}(\tau)+K_{[2]}^{*}(\tau)$ unchanged. However, subsidizing the technology not preferred in merit order, technology [2], incentivizes both a substitution effect (the $\delta_{[2]}$ arrow to the left) and a capacity expansion effect (the $\delta_{[2]}$ arrow to the right).

The intuition behind the result becomes clear through Proposition 1. In a portfolio consisting of both technologies, the fractile that defines merit-order-preferred capacity $K_{[1]}^{*}(\tau)$ is determined by the economics of both technologies. Therefore, subsidizing either technology shifts the fractile and increases the share of the subsidized technology in the optimal portfolio. However, total capacity $K_{[1]}^{*}(\tau)+K_{[2]}^{*}(\tau)=\bar{K}_{[2]}^{T}(\tau)$ depends only on the economics of the type less preferred in merit order in portfolios that include both technologies. In such portfolios, the rightmost edge of the firm's supply 


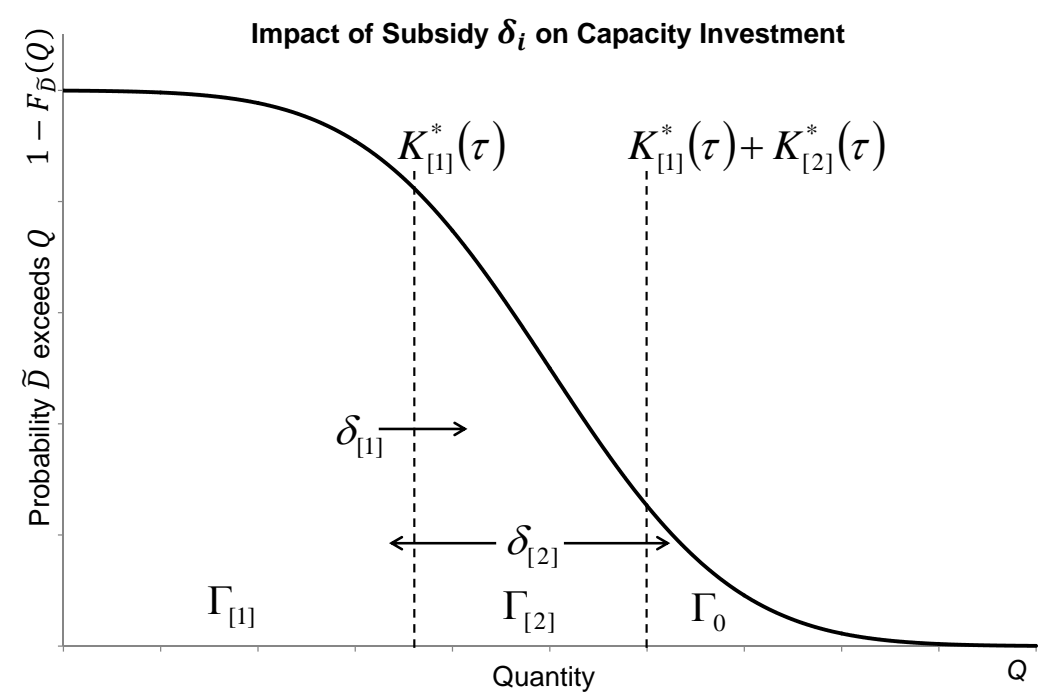

Figure 3 For mixed portfolios, subsidies of technology [1], $\delta_{[1]}$, increase $K_{[1]}^{*}(\tau)$, but not total capacity $K_{[1]}^{*}(\tau)+$ $K_{[2]}^{*}(\tau)$. Subsidies of technology [2], $\delta_{[2]}$, increase both $K_{[2]}^{*}(\tau)$ and total capcaity $K_{[1]}^{*}(\tau)+K_{[2]}^{*}(\tau)$.

curve is determined by the trade-off between the expected marginal cost and expected marginal revenue of an incremental unit of the technology least preferred in merit order. If clean technology is preferred in merit order, subsidizing it does not affect this trade-off and therefore does not alter the total capacity of the optimal portfolio.

If a subsidy results in a total capacity expansion, it can have an adverse effect on the emissions potential of the firm's portfolio, $\alpha_{1} K_{1}+\alpha_{2} K_{2}$, despite improving clean technology share. Corollary 5 summarizes this effect.

Corollary 5. Assume a per unit subsidy, $\delta$, without a binding budget constraint. If $\eta_{1}(\tau)>$ $\eta_{2}(\tau)$ and $K_{i}^{*}(\tau)>0 \forall i$, then the emissions potential of capacity increases due to:

a) Investment subsidy iff $\frac{\alpha_{1}-\alpha_{2}}{\alpha_{2}} \leq \frac{\left(\eta_{1}(\tau)-\eta_{2}(\tau)\right)}{\left(\eta_{2}(\tau)\right)} f_{\tilde{D}}\left(1-\frac{\beta_{1}+\gamma_{1}-\beta_{2}-\gamma_{2}}{\eta_{1}(\tau)-\eta_{2}(\tau)}\right) / f_{\tilde{D}}\left(1-\frac{\beta_{2}+\gamma_{2}}{\eta_{2}(\tau)}\right)$.

b) Production subsidy iff $\frac{\alpha_{1}-\alpha_{2}}{(1-\omega) \alpha_{2}} \leq \frac{\beta_{2}+\gamma_{2}}{\beta_{1}+\gamma_{1}-\beta_{2}-\gamma_{2}} \frac{\left(\eta_{1}(\tau)-\eta_{2}(\tau)\right)^{2}}{\left(\eta_{2}(\tau)\right)^{2}} f_{\tilde{D}}\left(1-\frac{\beta_{1}+\gamma_{1}-\beta_{2}-\gamma_{2}}{\eta_{1}(\tau)-\eta_{2}(\tau)}\right) / f_{\tilde{D}}\left(1-\frac{\beta_{2}+\gamma_{2}}{\eta_{2}(\tau)}\right)$.

Clean technology subsidies potentially have both an intensity and volume effect. By increasing the adoption of clean technology $K_{2}^{*}(\tau)$ and decreasing the adoption of dirty technology $K_{1}^{*}(\tau)$, subsidization of clean technology increases the optimal clean technology share, $\psi_{2}$. This reduces the emissions potential of capacity by decreasing the portfolio's average emissions intensity in expectation. If the clean type is favored in merit order, then a subsidy would not increase total capacity (evident through $\delta_{[1]}$ in Figure 3 above). With the subsidy decreasing emissions intensity while not affecting total capacity, it decreases the emissions potential of the firm's portfolio.

If, on the other hand, the dirty technology is favored in merit order (as stipulated by the condition $\eta_{1}(\tau)>\eta_{2}(\tau)$ in Corollary 5), a clean technology subsidy increases total capacity (per Corollary 4 and evident through $\delta_{[2]}$ in Figure 3 above). This implies, when dirty technology is favored in 
merit order, that the subsidy has opposing effects on the emissions potential of the firm's optimal capacity portfolio: it decreases emissions potential by increasing clean technology share (and therefore reducing the portfolio's average emissions intensity), but it increases emissions potential by increasing total capacity. Corollary 5 indicates the relative emissions intensity threshold at which the latter effect dominates, resulting in an increase in the emissions potential of the firm's optimal capacity portfolio as a consequence of clean technology investment subsidy (Corollary 5a) and production subsidy (Corollary 5b).

The conditions of Corollary 5 imply that unintentionally increasing the emissions potential of installed capacity through clean technology subsidization is an environmental risk in some scenarios, but not others. In which settings, and how, increases in the firm's emissions potential may arise due to clean technology subsidization can best be demonstrated through an illustrative example.

Illustrative example The data in Table 1 provide the levelized investment cost, fixed operating and maintenance $(\mathrm{O} \& \mathrm{M})$ cost, production cost, and emissions intensity for selected power generation technologies. ${ }^{7}$ Power generation is atypical relative to other capacity investment settings in that $100 \%$ of demand is generally served. In this setting, utility-owned reserves act as a backstop technology, generating power for otherwise unserved demand. The emissions intensity of reserve capacity is included in Table 1, but the investment and production costs are not since those are incurred by the utility itself, rather than the power generator.

\begin{tabular}{l|c|c|c|c}
\hline Technology & $\begin{array}{c}\text { Firm's Levelized } \\
\text { Investment Cost } \\
\beta_{i}\end{array}$ & $\begin{array}{c}\text { Firm's Fixed } \\
\text { O\&M Cost } \\
\gamma_{i}\end{array}$ & $\begin{array}{c}\text { Firm's Direct } \\
\text { Prod. Cost } \\
b_{i}\end{array}$ & $\begin{array}{c}\text { Emissions } \\
\text { Intensity } \\
\alpha_{i}\end{array}$ \\
\hline \hline Solar Photovoltaic & $\$ 109.8$ & $\$ 11.4$ & $\$ 0$ & 0.00 tons \\
Combined Cycle Gas & $\$ 15.9$ & $\$ 2.0$ & $\$ 53.6$ & 0.40 tons \\
Combined Cycle Gas CCS & $\$ 30.1$ & $\$ 4.2$ & $\$ 64.6$ & 0.05 tons \\
Gas Turbine Reserves & - & - & - & 0.42 tons \\
\hline
\end{tabular}

Table 1 Per-Megawatt Hour costs and emissions intensity for select power generation technologies. Sources: US Energy Information Administration (2014), US Department of Energy (2013), Fripp (2011)

With negligible production cost and emissions intensity, solar technology would be preferred in merit order. Therefore, by Corollary 4, the generator's total capacity would not increase as a consequence of the subsidy. Figure 3 above illustrates this point, with $\delta_{[1]}$ representing a subsidy of solar photovoltaic technology. Such a subsidy would also increase clean capacity and decrease dirty capacity in the optimal portfolio. As a consequence of these three effects, subsidizing solar technology decreases the emissions potential of the generator's portfolio.

${ }^{7}$ Levelized investment costs are the per-megawatt hour capital cost (in real dollars) of a power generation plant; i.e., they are the quotient of capital costs and total output expected over the plant's financial life. Levelized costs account for capital cost, financing cost and assumed utilization rate (including assumed availability for solar photovoltaics). 
Likewise, a production subsidy of carbon capture and storage (CCS) gas technology would also decrease the emissions potential of the firm's portfolio. Given the investment cost disadvantage of CCS gas (relative to conventional gas), such a subsidy $\delta_{C C S}$ would have to reduce the total per unit operating cost of CCS gas to a level below that of conventional gas for the CCS technology to be included in the firm's portfolio-i.e., the condition $\eta_{C C S}(\tau)+\delta_{C C S}-\beta_{C C S}-\gamma_{C C S}>\eta_{G A S}(\tau)-$ $\beta_{G A S}-\gamma_{G A S}$ must be satisfied per Proposition 1, with $\beta_{C C S}+\gamma_{C C S}>\beta_{G A S}+\gamma_{G A S}$ per Table 1. Such a subsidy would cause CCS gas to enter the firm's portfolio from the left in Figure 4a, i.e., in preferred merit order. The subsidy would consequently cause CCS gas to displace conventional gas in the optimal portfolio while the generator's total capacity would remain unaffected, thereby decreasing the emissions potential of the generator's capacity portfolio.

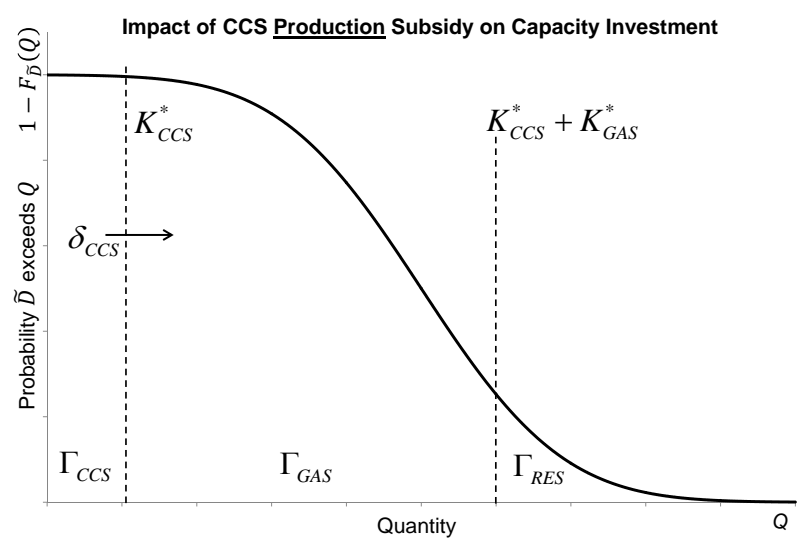

(a)

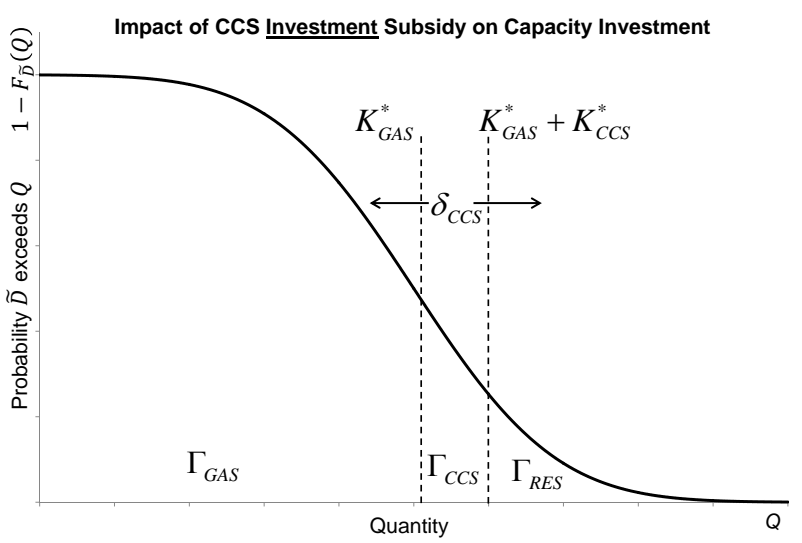

(b)

Figure 4 Production and investment subsidies of CCS gas affect merit order differently. This results in total capacity $K_{C C S}^{*}+K_{G A S}^{*}$ increasing as a consequence of investment subsidy (but not production subsidy).

An investment subsidy of CCS natural gas, on the other hand, may increase the emissions potential of the generator's capacity. Given its greater production cost relative to conventional gas, CCS gas capacity would only be included in the generator's portfolio if its subsidized fixed costs were sufficiently less than the fixed costs of conventional gas capacity; i.e., if $\left(\beta_{C C S}-\delta_{C C S}+\right.$ $\left.\gamma_{C C S}\right) / \eta_{C C S}(\tau)<\left(\beta_{G A S}+\gamma_{G A S}\right) / \eta_{G A S}(\tau)$ per Proposition 1. With production costs unaffected by the subsidy, conventional gas capacity would be preferred in merit order provided that emissions price is less than the breakeven for the technologies; i.e., $\tau<\left(b_{C C S}-b_{G A S}\right) /\left(\alpha_{G A S}-\alpha_{C C S}\right)$. As the lower dispatch priority, CCS gas capacity would be added to the generator's portfolio to serve the most speculative demand, entering the portfolio from the right of Figure 4b. The subsidy $\delta_{C C S}$ would decrease the conventional gas capacity $K_{G A S}^{*}$ in the generator's optimal portfolio while increasing the total capacity $K_{G A S}^{*}+K_{C C S}^{*}$ (per Corollary 4). If the inequality in Corollary 5a holds, this increase in total capacity would be sufficient to increase the emissions potential of the generator's capacity portfolio. In this setting, since $\alpha_{C C S}<\alpha_{R E S}$, the increased expected demand served 
by the generator's CCS capacity $\left(\Gamma_{C C S}\right)$ would reduce the expected emissions of delivered power by displacing expected demand served by the greater emissions-intensity, utility-owned reserves $\left(\Gamma_{R E S}\right)$. This arises due to the existence of a backstop technology to ensure that $100 \%$ of demand is met. In settings without a backstop, an increase in the emissions potential of the firm's capacity portfolio would result in an increase in expected emissions of delivered goods.

To summarize, due to demand hedging, the firm's total capacity is determined by the economics of the technology least preferred in merit order (as described following Proposition 1). If the clean technology is the type least preferred in merit order, then subsidization improves the economics of the total-capacity-determining type and the firm's optimal capacity portfolio expands (Corollary 4). This conditionally increases the emissions potential of the firm's optimal portfolio, despite the increased clean technology share (Corollary 5a and 5b). If, on the other hand, the clean technology is not the least preferred in merit order, then its economics do not determine the firm's optimal total capacity. In this case, subsidization decreases the emissions potential of the firm's capacity by increasing the clean technology's share of the portfolio without increasing total capacity.

\section{Conclusions}

With aggregate consumption expected to grow for the foreseeable future (Drake and Spinler 2013; Plambeck and Toktay 2013), it is imperative to understand how climate policy mechanisms influence the use of clean technology. To that end, we study the effect of emissions regulation and clean technology subsidies on a firm's capacity portfolio and production decisions. We then study the implications of those decisions on expected profit and the emissions potential of the firm's capacity.

Contrary to recent arguments (e.g., Metcalf 2009; Parry and Pizer 2007), we show that emissions price uncertainty under cap-and-trade regulation results in greater expected profit for the firm than a constant rate under an emissions tax. We identify two mechanisms driving this expected profit difference: the firm's option not to operate capacity in its portfolio; and dispatch flexibility, which is the firm's ability to respond to emissions price realizations when deciding which technologies in its portfolio to first deploy. The firm benefits from the former under two conditions: i) emissions price can be sufficiently great that a technology in the firm's portfolio is unprofitable to operate; and ii) demand can exceed the capacity of profitable capacity in the firm's portfolio. The firm benefits from dispatch flexibility under three conditions: i) the firm's portfolio includes clean and dirty technology; ii) emissions price can be great enough (low enough) that the firm's clean (dirty) technology yields the lowest operating cost; and iii) expected utilization is less than $100 \%$.

We also explore the efficacy of climate policy levers. We show that increases in emissions tax rate can decrease investment in clean technology if it has the greater production cost and is not sufficiently cleaner than the conventional alternative. We also show that investment and production 
subsidies have distinct effects on the firm's capacity portfolio decisions. Both subsidy mechanisms increase a technology's expected marginal profit. However, investment subsidies decrease the firm's ex ante risk, while production subsidies decrease operating costs and thereby potentially influence dispatch order. This difference affects the role that the technology plays in the firm's portfolio and ensuing environmental implications.

In settings where a technology's unsubsidized production and investment cost both exceed conventional alternatives (as is the case with CCS technologies), subsidization determines not only whether the technology is included in the firm's capacity portfolio, but also how the technology is integrated into the firm's portfolio: i) as the higher profit margin, dispatch-prioritized technology (production subsidy); or ii) as the lower investment risk, demand-hedging technology (investment subsidy). In portfolios consisting of multiple technologies, production subsidies imply that each subsidized unit of capacity will have a greater expected utilization than it would under an investment subsidy. Investment subsidies, on the other hand, imply a greater rate of substitution (displacement of dirty technology with clean technology), but they also imply that the firm's total capacity (and, conditionally, its emissions potential) increases as a consequence of subsidy.

\section{References}

Aflaki, S., S. Netessine. 2015. Strategic investment in renewable energy sources: The effect of supply intermittency. Working paper, INSEAD.

Aldy, J. E., W. A. Pizer. 2013. The Employment and Competitiveness Impacts of Power-Sector Regulations. Does Regulation Kill Jobs?, University of Pennsylvania Press, Philadelphia, USA, 70-88.

Bernstein, M. A., J. Griffin. 2005. Regional differences in the price-elasticity of demand for energy. Technical report, RAND Corporation, Santa Monica, CA. http://www.rand.org/content/dam/rand/pubs/technical_reports/2005/RAND_TR292.pdf. Accessed April 30, 2015.

Bish, E. K., Q. Wang. 2004. Optimal investment strategies for flexible resources, considering pricing and correlated demands. Operations Research 52(6) 954-964.

Boston Consulting Group. 2008. Assessment of the impact of the 2013-2020 ETS proposal on the European cement industry .

Boston Consulting Group. 2012. The cement sector: A strategic contributor to Europe's future. Available at http://tinyurl.com/obt5ng6. Accessed July 3, 2014. .

Boyabatli, O., L. B. Toktay. 2011. Stochastic capacity investment and flexible vs. dedicated technology choice in imperfect capital markets. Management Science 57(12) 2163-2179.

Caro, F., C. J. Corbett, T. Tan, R. Zuidwijk. 2013. Double-counting in supply chain carbon footprinting. Manufacturing \&3 Service Operations Management 15(4) 545-558. 
Chen, Y., C-L Tseng. 2011. Inducing clean technology in the elecricity sector: Tradeable permits or carbon tax policies. The Energy Journal 32(3) 149-174.

Crew, M. A., C. S. Fernando, P. R. Kleindorfer. 1993. The theory of peak-load pricing: a survey. Journal of Regulatory Economics 8(3) 215-248.

Crew, M. A., P. R. Kleindorfer. 1976. Peak load pricing with a diverse technology. The Bell Journal of Economics 7(1) 207-231.

Database of State Incentives for Renewables \& Efficiency. 2014. Financial incentives for renewable energy. Available at http://www.dsireusa.org/summarytables/finre.cfm. Accessed September 16, 2014 .

Drake, D. F. 2015. Carbon tariffs: Effects in settings with technology choice and foreign production cost advantage. Working paper, Harvard Business School.

Drake, D. F., S. Spinler. 2013. Sustainable operations management: An enduring stream or passing fancy? Manufacturing \& Service Operations Management 15(4) 689-700.

Fine, C., R. Freund. 1990. Optimal investment in product flexible technology. Management Science 36(4) $449-466$.

Fripp, M. 2011. Greenhouse gas emissions from operating reserves used to backup large-scale wind power. Environmental Science \& Technology 45(21) 9405-9412.

Goyal, M., S. Netessine. 2007. Strategic technology choice and capacity investment under demand uncertainty. Management Science 53(2) 192-207.

Goyal, M., S. Netessine. 2011. Volume flexibility, product flexibility, or both: The role of demand correlation and product substitution. Manufacturing \& Service Operations Management 13(2) 180-193.

Harrison, J., J. A. Van Mieghem. 1999. Multi-resource investment strategies: Operational hedging under demand uncertainty. European Journal of Operational Research 113(1) 17-29.

H.R. 1337. America's Energy Security Trust Fund Act of 2009, 111th US Congress, 1st Session. (2009).

H.R. 1666. Safe Markets Development Act of 2009, 111th US Congress, 1st Session. (2009).

H.R. 1759. Emission Migration Prevention with Long-term Output Yields Act, 111th US Congress, 1st Session. (2009).

H.R. 2380. Raise Wages, Cut Carbon Act of 2009, 111th US Congress, 1st Session. (2009).

H.R. 2454. American Clean Energy and Security Act of 2009, 111th US Congress, 1st Session. (2009).

H.R. 594. Save Our Climate Act of 2009, 111th US Congress, 1st Session. (2009).

İşlegen, Ö., E. L. Plambeck, T. Taylor. 2015. Variability in emissions-cost: Implications for facility location, production and trade. Work-in-progress discussed with corresponding author.

İşlegen, Ö., S. J. Reichelstein. 2011. Carbon capture by fossil fuel power plants: An economic analysis. Management Science 57(1) 21-39. 
Inglis, B., A. Laffer. 2008. December 28. An Emissions Plan Conservatives Could Warm To. The New York Times (online edition).

International Energy Agency. 2014. IEA/IRENA joint policies and measures database. Available at http://www.iea.org/policiesandmeasures/renewableenergy/. Accessed September 16, 2014 .

Jaffe, A. B., R. G. Newell, R. N. Stavins. 2003. Technological Change and the Environment. Volume 1 ed. Handbook of Environmental Economics, Elsevier Science, Amsterdam, The Netherlands, 461-516.

Jowit, J. 2010. August 30. Bjørn Lomborg: \$100bn a Year Needed to Fight Climate Change. The Guardian (online edition).

Krass, D., T. Nedorezov, A. Ovchinnikov. 2013. Environmental taxes and the choice of green technology. Production and Operations Management 22(5) 1035-1055.

Krysiak, F. C. 2008. Prices vs. quantities: The effects on technology choice. Journal of Public Economics 92(56) 1275-1287.

La Cour, L. F., H. P. Mollgaard. 2002. Market domination: Tests applied to the Danish cement industry. European Journal of Law and Ecoomics 14 99-127.

Mathiesen, L., O. Moestad. 2004. Climate policy and the steel industry: Achieving global emission reductions by an incomplete climate agreement. The Energy Journal 25(4) 91-114.

McKinsey and Company. 2006. EU ETS review: Report on international competitiveness. Available at http://ec.europa.eu/clima/policies/ets/docs/report_int_competitiveness_20061222_en.pdf. Accessed April 28, 2015. .

Metcalf, G. E. 2009. Cost containment in climate change policy: Alternative approaches to mitigating price volatility. Working paper 15125, National Bureau of Economic Research.

Miller, N. H., M. Osborne. 2010. Competition among spatially differentiated firms: An empirical model with an application to cement. Federal Trade Commission working paper available at http://www.ftc.gov/sites/default/files/documents/public_events/3rd-annual-microeconomicsconference/nmiller.pdf. Accessed April 28, 2015 .

Moulin, H. 1984. Dominance solvability and Cournot stability. Mathematical Social Sciences 7(1) 83-102.

Netessine, S., G. Dobson, R. A. Shumsky. 2002. Flexible service capacity: Optimal investment and the impact of demand correlation. Operations Research 50(2) 375-388.

Parry, I. W. H., W. A. Pizer. 2007. Emissions trading versus $\mathrm{CO}_{2}$ taxes. Washington DC: Resources for the Future.

Plambeck, E. L., L. B. Toktay. 2013. Introduction to the special issue on the environment. Manufacturing \& Service Operations Management 15(4) 523-526.

Ponssard, J. P., N. Walker. 2008. EU emissions trading and the cement sector: A spatial competition analysis. Climate Policy 8(5) 467-493. 
Pontin, J. 2010. August 24. Q\&A: Bill Gates. Technology Review (online edition).

Requate, T. 1998. Incentives to innovate under emission taxes and tradeable permits. European Journal of Political Economy 14(1) 139-165.

Requate, T. 2005. Timing and commitment of environmental policy, adoption of new technology, and repercussions on R\&D. Environmental and Resource Economics 31(2) 175-199.

Requate, T., W. Unold. 2003. Environmental policy incentives to adopt advanced abatement technology: Will the true ranking please stand up? European Economic Review 47(1) 125-146.

S. 1733. Clean Energy Jobs and American Power Act of 2009, 111th US Congress. (2009).

Tomlin, B., Y. Wang. 2005. On the value of mix flexibility and dual sourcing in unreliable newsvendor networks. Manufacturing \& Service Operations Management 7(1) 37-57.

US Department of Energy. 2013. Cost and performance baseline for fossil energy plants volume 1: Bituminous coal and natural gas to electricity. Available at http://www.netl.doe.gov/file\%20library/research/energy\%20analysis/oe/bitbase_finrep_rev2a3_20130919_1.pdf Accessed september 23, 2014 .

US Energy Information Administration. 2008. Energy market and economic impacts of S.2191, the Lieberman-Warner Climate Security Act of 2007. Available at http://www.eia.gov/oiaf/servicerpt/s2191/pdf/sroiaf(2008)01.pdf. Accessed April 30, 2015.

US Energy Information Administration. 2014. Levelized cost and levelized avoided cost of new generation resources in the Annual Energy Outlook 2014. Available at http://www.eia.gov/forecasts/aeo/pdf/electricity_generation.pdf Accessed september 18, 2014 .

US Environmental Protection Agency. 2009. EPA analysis of the American Clean Energy and Security Act of 2009 H.R.2454 in the 111th Congress. Available at http://www.epa.gov/climatechange/Downloads/EPAactivities/HR2454_Analysis.pdf. Accessed April $30,2015$.

US Environmental Protection Agency. 2010. EPA analysis of the American Power Act in the 111th Congress. Available at http://www.epa.gov/climatechange/Downloads/EPAactivities/EPA_APA_Analysis_6-1410.pdf. Accessed April 30, 2015.

Wang, W., M. E. Ferguson, S. Hu, G. C. Silva. 2013. Dynamic capacity investment with two competing technologies. Manufacturing \& Service Operations Management 15(4) 616-629.

Zhao, J. 2003. Irreversible abatement investment under cost uncertainties: Tradable emission permits and emissions charges. Journal of Public Economics 87(12) 2765-2789.

Zhao, J., B. F. Hobbs, J-S Pang. 2010. Long-run equilibrium modeling of emissions allowance allocation systems in electric power markets. Operations Research 58(3) 529-548.

\section{Appendix. Proofs}


Proof of concavity in emissions tax setting. Concavity can be proven directly through the Hessian, with the Hessian in the emissions tax setting, $H(\Pi)$, defined by

where

$$
H(\Pi)=\left[\begin{array}{cc}
\frac{\partial^{2} \Pi}{\partial K_{1]}^{2}} & \frac{\partial^{2} \Pi}{\partial K_{[1]} \partial K_{[2]}} \\
\frac{\partial^{2} \Pi}{\partial K_{[1]} \partial K_{[2]}} & \frac{\partial^{\Pi} \Pi}{\partial K_{[2]}^{2}}
\end{array}\right]
$$

$$
\begin{gathered}
\frac{\partial^{2} \Pi}{\partial K_{[1]}^{2}}=-f_{\tilde{D}}\left(K_{[1]}\right)\left(\eta_{[1]}(\tau)-\eta_{[2]}(\tau)\right)-f_{\tilde{D}}\left(K_{[1]}+K_{[2]}\right) \eta_{[2]}(\tau), \\
\frac{\partial^{2} \Pi}{\partial K_{[2]}^{2}}=-f_{\tilde{D}}\left(K_{[1]}+K_{[2]}\right) \eta_{[2]}(\tau),
\end{gathered}
$$

and

$$
\frac{\partial^{2} \Pi}{\partial K_{[1]} \partial K_{[2]}}=-f_{\tilde{D}}\left(K_{[1]}+K_{[2]}\right) \eta_{[2]}(\tau) .
$$

The first order leading principal minor is defined by $(7)$ and is non-positive given that $\eta_{[1]}(\tau)>\eta_{[2]}(\tau)>0$ by merit ordering and the assumption that $\eta_{[i]}(\tau)-\beta_{i}-\gamma_{i}>0$. This principal minor is strictly negative when $f_{\tilde{D}}\left(K_{[1]}\right)>0$ and/or $f_{\tilde{D}}\left(K_{[1]}+K_{[2]}\right)>0$.

The second order leading principal minor is defined by the determinant of the Hessian, $|H(\Pi)|$, where

$$
|H(\Pi)|=\left(f_{\tilde{D}}\left(K_{[1]}+K_{[2]}\right) \eta_{[2]}(\tau)\right)\left(f_{\tilde{D}}\left(K_{[1]}\right)\left(\eta_{[1]}(\tau)-\eta_{[2]}(\tau)\right)\right) .
$$

The second leading principal minor is clearly non-negative, and is strictly positive given $f_{\tilde{D}}\left(K_{[1]}\right)>0$ and $f_{\tilde{D}}\left(K_{[1]}+K_{[2]}\right)>0$. Thus, the matrix $H(\Pi)$ is semi-negative definite. It is negative definite whenever $f_{\tilde{D}}\left(K_{[1]}\right)>0$ and $f_{\tilde{D}}\left(K_{[1]}+K_{[2]}\right)>0$. Therefore, $\Pi$ is concave in capacities $K_{[1]}$ and $K_{[2]}$, and strictly concave in $K_{[1]}$ and $K_{[2]}$ when $f_{\tilde{D}}\left(K_{[1]}\right)>0$ and $f_{\tilde{D}}\left(K_{[1]}+K_{[2]}\right)>0$.

Proof of Proposition 1. Substituting (2) into the firm's objective in the emissions tax setting given by (3), then transforming the min arguments with positive parts yields

$$
\begin{gathered}
\max _{K_{[1]}, K_{[2]}} \Pi(\tilde{D}, \tau)=\sum_{i=1}^{2} \mathbb{E}\left[\eta_{[i]}(\tau)(\tau)\left(\left(\tilde{D}-\sum_{k=1}^{i-1} K_{[k]}\right)^{+}-\left(\tilde{D}-\sum_{k=1}^{i} K_{[k]}\right)^{+}\right)\right]-\mathbb{E}[r \tilde{D}]-\sum_{i=1}^{2}\left(\beta_{[i]}+\gamma_{[i]}\right) K_{[i]} \\
\text { s.t. } K_{i} \geq 0, \forall i .
\end{gathered}
$$

Solving (9) for FOCs yields

$$
\frac{\partial \Pi}{\partial K_{[i]}}=\left(1-F_{\tilde{D}}\left(\sum_{k=1}^{i} K_{[k]}\right)\right) \eta_{[i]}(\tau)-\sum_{l=i+1}^{2}\left[F_{\tilde{D}}\left(\sum_{k=1}^{l} K_{[k]}\right)-F_{\tilde{D}}\left(\sum_{k=1}^{l-1} K_{[k]}\right)\right] \eta_{[l]}(\tau)-\beta_{[i]}-\gamma_{[i]}=0 .
$$

Solving (10) for $i=2$ yields total installed capacity,

$$
K_{[1]}^{*}(\tau)+K_{[2]}^{*}(\tau)=F_{\tilde{D}}^{-1}\left(1-\frac{\beta_{[2]}+\gamma_{[2]}}{\eta_{[2]}(\tau)}\right) .
$$

Solving (10) for $i=1$ yields the solution for the preferred type,

$$
K_{[1]}^{*}(\tau)=F_{\tilde{D}}^{-1}\left(1-\frac{\beta_{[1]}+\gamma_{[1]}-\beta_{[2]}-\gamma_{[2]}}{\eta_{[1]}(\tau)-\eta_{[2]}(\tau)}\right) .
$$

Type [2] capacity is the difference between (11) and (12). Boundary conditions follow from the requirement that the argument in (12) be non-negative and the requirement that the difference between (11) and (12) be non-negative. 
Proof of concavity in emissions cap-and-trade setting. As with concavity in the emissions tax setting, concavity in the cap-and-trade setting can be proven directly through the Hessian,

$$
H(\hat{\Pi})=\left[\begin{array}{cc}
\frac{\partial^{2} \hat{\Pi}}{\partial \hat{K}_{1}^{2}} & \frac{\partial^{2} \hat{\Pi}}{\partial \hat{K}_{1} \partial \hat{K}_{2}} \\
\frac{\partial^{2} \hat{\Pi}}{\partial \hat{K}_{1} \partial \hat{K}_{2}} & \frac{\partial^{2} \hat{\Pi}}{\partial \hat{K}_{2}^{2}}
\end{array}\right] .
$$

where

$$
\begin{aligned}
\frac{\partial^{2} \hat{\Pi}}{\partial \hat{K}_{1}^{2}} & =-f_{\tilde{D}}\left(\hat{K}_{1}+\hat{K}_{2}\right) \bar{\eta}_{2}\left(\tilde{e}_{1}\right)-f_{\tilde{D}}\left(\hat{K}_{1}\right)\left(\bar{\eta}_{1}\left(\tilde{e}_{1}\right)-\bar{\eta}_{2}\left(\tilde{e}_{1}\right)\right)-f_{\tilde{D}}\left(\hat{K}_{1}+\hat{K}_{2}\right) \bar{\eta}_{1}\left(\tilde{e}_{2}\right)-f_{\tilde{D}}\left(\hat{K}_{1}\right) \bar{\eta}_{1}\left(\tilde{e}_{3,1}\right), \\
\frac{\partial^{2} \hat{\Pi}}{\partial \hat{K}_{2}^{2}} & =-f_{\tilde{D}}\left(\hat{K}_{1}+\hat{K}_{2}\right) \bar{\eta}_{1}\left(\tilde{e}_{2}\right)-f_{\tilde{D}}\left(\hat{K}_{2}\right)\left(\bar{\eta}_{2}\left(\tilde{e}_{2}\right)-\bar{\eta}_{1}\left(\tilde{e}_{2}\right)\right)-f_{\tilde{D}}\left(\hat{K}_{1}+\hat{K}_{2}\right) \bar{\eta}_{2}\left(\tilde{e}_{1}\right)-f_{\tilde{D}}\left(\hat{K}_{2}\right) \bar{\eta}_{2}\left(\tilde{e}_{3,2}\right), \\
\quad \text { and } & \\
\frac{\partial^{2} \hat{\Pi}}{\partial \hat{K}_{1} \partial \hat{K}_{2}} & =-f_{\tilde{D}}\left(\hat{K}_{1}+\hat{K}_{2}\right) \bar{\eta}_{1}\left(\tilde{e}_{2}\right)-f_{\tilde{D}}\left(\hat{K}_{1}+\hat{K}_{2}\right) \bar{\eta}_{2}\left(\tilde{e}_{1}\right) .
\end{aligned}
$$

The first order leading principal minor of $H(\hat{\Pi})$ is defined by $\frac{\partial^{2} \hat{\Pi}}{\partial \hat{K}_{1}^{2}}$, which is non-positive given the definition of $\bar{\eta}_{i}(\cdot)$ and of merit order intervals $\tilde{e}_{j}$. This principal minor becomes strictly negative if $f_{\tilde{D}}\left(\hat{K}_{1}+\hat{K}_{2}\right)>0$ or $f_{\tilde{D}}\left(\hat{K}_{1}\right)>0$.

The second order leading principal minor of the Hessian is given by its determinant, $|H(\hat{\Pi})|$, where

$$
|H(\hat{\Pi})|=\left(\frac{\partial^{2} \hat{\Pi}}{\partial \hat{K}_{1}^{2}}\right)\left(\frac{\partial^{2} \hat{\Pi}}{\partial \hat{K}_{2}^{2}}\right)-\left(\frac{\partial^{2} \hat{\Pi}}{\partial \hat{K}_{1} \partial \hat{K}_{2}}\right)^{2} .
$$

Note that $0 \geq \frac{\partial^{2} \hat{\Pi}}{\partial \hat{K}_{1} \partial \hat{K}_{2}} \geq \frac{\partial^{2} \hat{\Pi}}{\partial \hat{K}_{1}^{2}}$, with the inequalities strict when $f_{\tilde{D}}\left(\hat{K}_{1}\right)>0$. Also note that $0 \geq$ $\frac{\partial^{2} \hat{\Pi}}{\partial \hat{K}_{1} \partial \hat{K}_{2}} \geq \frac{\partial^{2} \hat{\Pi}}{\partial \hat{K}_{2}^{2}}$, with the inequalities strict when $f_{\tilde{D}}\left(\hat{K}_{2}\right)>0$. Therefore (15) is non-negative, and strictly positive when two or more of the following hold:

$$
f_{\tilde{D}}\left(\hat{K}_{1}\right)>0, \quad f_{\tilde{D}}\left(\hat{K}_{2}\right)>0, \quad \text { and } \quad f_{\tilde{D}}\left(\hat{K}_{1}+\hat{K}_{2}\right)>0 .
$$

Therefore, $\hat{\Pi}(\cdot)$ is concave in capacities $\hat{K}_{1}$ and $\hat{K}_{2}$ and strictly concave in these capacities when two or more of the conditions in (16) hold.

Proof of Proposition 2. Letting $f_{\tilde{e}}$ represent the density function for emissions price, first order conditions of (6) are symmetric and given by

$$
\begin{aligned}
\frac{\partial \hat{\Pi}}{\partial \hat{K}_{i}}= & \int_{x \in \tilde{e}_{i}} f_{\tilde{e}}(x)\left[\left(F_{\tilde{D}}\left(\hat{K}_{i}+\hat{K}_{-i}\right)-F_{\tilde{D}}\left(\hat{K}_{i}\right)\right)\left(\eta_{i}(x)-\eta_{-i}(x)\right)\right] \mathrm{d} x \\
& +\int_{x \in \tilde{e}_{i}} f_{\tilde{e}}(x)\left[\left(1-F_{\tilde{D}}\left(\hat{K}_{i}+\hat{K}_{-i}\right)\right) \eta_{i}(x)\right] \mathrm{d} x \\
& +\int_{x \in \tilde{e}_{-i}} f_{\tilde{e}}(x)\left[\left(1-F_{\tilde{D}}\left(\hat{K}_{i}+\hat{K}_{-i}\right)\right) \eta_{i}(x)\right] \mathrm{d} x \\
& +\int_{x \in \tilde{e}_{3, i}} f_{\tilde{e}}(x)\left[\left(1-F_{\tilde{D}}\left(\hat{K}_{i}\right)\right) \eta_{i}(x)\right] \mathrm{d} x-\beta_{i}-\gamma_{i}=0 .
\end{aligned}
$$


Assume that type 1 dominates merit order in stage 2 . In such a case, $\tilde{e}_{2}$ and $\tilde{e}_{3,2}$ are empty. As a result, solving (17) for total capacity, $\hat{K}_{1}^{*}(\tilde{e})+\hat{K}_{2}^{*}(\tilde{e})$, yields

$$
\begin{aligned}
\hat{K}_{1}^{*}(\tilde{e})+\hat{K}_{2}^{*}(\tilde{e}) & =F_{\tilde{D}}^{-1}\left(\frac{\bar{\eta}_{2}\left(\tilde{e}_{1}\right)-\beta_{2}-\gamma_{2}}{\bar{\eta}_{2}\left(\tilde{e}_{1}\right)}\right) \\
& =F_{\tilde{D}}^{-1}\left(1-\frac{\beta_{2}+\gamma_{2}}{\bar{\eta}_{2}\left(\tilde{e}_{1}\right)}\right) .
\end{aligned}
$$

Substituting (18) into (17) provides the solution for type 1, the merit order dominant technology,

$$
\begin{aligned}
\hat{K}_{1}^{*}(\tilde{e}) & =F_{\tilde{D}}^{-1}\left(\frac{\bar{\eta}_{1}\left(\tilde{e}_{1}\right)+\bar{\eta}_{1}\left(\tilde{e}_{3,1}\right)-\beta_{1}-\gamma_{1}-\bar{\eta}_{2}\left(\tilde{e}_{1}\right)+\beta_{2}+\gamma_{2}}{\bar{\eta}_{1}\left(\tilde{e}_{1}\right)+\bar{\eta}_{1}\left(\tilde{e}_{3,1}\right)-\bar{\eta}_{2}\left(\tilde{e}_{1}\right)}\right) \\
& =F_{\tilde{D}}^{-1}\left(1-\frac{\beta_{1}+\gamma_{1}-\beta_{2}-\gamma_{2}}{\bar{\eta}_{1}\left(\tilde{e}_{1}\right)+\bar{\eta}_{1}\left(\tilde{e}_{3,1}\right)-\bar{\eta}_{2}\left(\tilde{e}_{1}\right)}\right) .
\end{aligned}
$$

The difference between (18) and (19) yields interior solutions for type 2 capacity.

Boundary conditions are obtained by the requirement that the argument in (19) be non-negative, and the requirement that the difference in the argument in (18) and (19) be non-negative. Interior solutions and conditions when type 2 dominates the second stage are solved symmetrically.

Proof of Proposition 3. Given that neither type dominates, both $\tilde{e}_{1}$ and $\tilde{e}_{2}$ are non-empty. Therefore, solving (17) for total installed capacity, $\left\{\hat{K}_{1}+\hat{K}_{2}\right\}^{*}\left(\hat{K}_{2}, \tilde{e}\right)$, yields

$$
\left\{\hat{K}_{1}+\hat{K}_{2}\right\}^{*}\left(\hat{K}_{2}, \tilde{e}\right)=F_{\tilde{D}}^{-1}\left[\frac{\bar{\eta}_{2}\left(\tilde{e}_{1}\right)+\bar{\eta}_{2}\left(\tilde{e}_{2}\right)+\bar{\eta}_{2}\left(\tilde{e}_{3,2}\right)-\beta_{2}-\gamma_{2}}{\bar{\eta}_{2}\left(\tilde{e}_{1}\right)+\bar{\eta}_{1}\left(\tilde{e}_{2}\right)}-F_{\tilde{D}}\left(\hat{K}_{2}\right) \frac{\bar{\eta}_{2}\left(\tilde{e}_{2}\right)+\bar{\eta}_{2}\left(\tilde{e}_{3,2}\right)-\bar{\eta}_{1}\left(\tilde{e}_{2}\right)}{\bar{\eta}_{2}\left(\tilde{e}_{1}\right)+\bar{\eta}_{1}\left(\tilde{e}_{2}\right)}\right] .
$$

Substituting (20) into (17), followed by standard algebra to isolate $\hat{K}_{1}^{*}\left(\hat{K}_{2}, \tilde{e}\right)$ yields a solution for type 1 capacity, dependent on type 2 capacity;

$$
\hat{K}_{1}^{*}\left(\hat{K}_{2}, \tilde{e}\right)=F_{\tilde{D}}^{-1}\left[\left(1-\frac{\beta_{1}+\gamma_{1}-\beta_{2}-\gamma_{2}}{\bar{\eta}_{1}\left(\tilde{e}_{1}\right)+\bar{\eta}_{1}\left(\tilde{e}_{3,1}\right)-\bar{\eta}_{2}\left(\tilde{e}_{1}\right)}\right)-\left(1-F_{\tilde{D}}\left(\hat{K}_{2}\right)\right) \frac{\bar{\eta}_{2}\left(\tilde{e}_{2}\right)+\bar{\eta}_{2}\left(\tilde{e}_{3,2}\right)-\bar{\eta}_{1}\left(\tilde{e}_{2}\right)}{\bar{\eta}_{1}\left(\tilde{e}_{1}\right)+\bar{\eta}_{1}\left(\tilde{e}_{3,1}\right)-\bar{\eta}_{2}\left(\tilde{e}_{1}\right)}\right] .
$$

The solution for type 2 capacity is symmetric.

We solve for boundary conditions through the following lemma,

Lemma 1. Given $\frac{\partial^{2} \hat{\Pi}}{\partial \hat{K}_{i} \partial \hat{K}_{-i}} \leq 0$, then $\left.\frac{\partial \hat{\Pi}}{\partial \hat{K}_{i}}\right|_{\hat{K}_{i}=0} \leq 0$ implies $\hat{K}_{i}^{*}(\tilde{e})=0$ and $\hat{K}_{-i}^{*}(\tilde{e})=\bar{K}_{-i}^{C}(\tilde{e})$.

Proof of Lemma 1. $\left.\frac{\partial \hat{\Pi}}{\partial \hat{K}_{i}}\right|_{\hat{K}_{i}=0} \leq 0$ implies $\hat{K}_{i}^{*}\left(\hat{K}_{-i}, \tilde{e}\right)=0$ through the concavity of $\hat{\Pi}(\cdot)$ in $\hat{K}_{i}$. Since $\frac{\partial^{2} \hat{\Pi}}{\partial \hat{K}_{i} \partial \hat{K}_{-i}} \leq 0, \hat{K}_{i}^{*}\left(\hat{K}_{-i}, \tilde{e}\right)=0$ implies $\hat{K}_{-i}^{*}\left(\hat{K}_{i}, \tilde{e}\right)=\bar{K}_{-i}^{C}(\tilde{e})$ by the definition of $\bar{K}_{-i}^{C}(\tilde{e})$.

It is evident from (14) that capacities are strategic substitutes, and therefore Lemma 1 holds. The boundary conditions follow directly from Lemma 1 and (17).

Proof of Proposition 4. The proof requires the following lemma,

Lemma 2. The solution set in the cap-and-trade setting is non-empty and compact.

That the solution set is non-empty follows trivially from the zero vector as a feasible solution. Through the negative cross-partial of $\hat{\Pi}(\cdot)$, we have established $\bar{K}_{i}^{C}(\tilde{e})$ as the effective upper bound 
for type $i$ capacity, $i \in\{1,2\}$, and 0 is the lower bound. Therefore, the solution set can be restricted to the closed and bounded Euclidean space $\left\{\hat{K}_{1}, \hat{K}_{2} \mid 0 \leq \hat{K}_{i} \leq \bar{K}_{i}^{C}(\tilde{e}), \quad i \in N\right\}$.

Moulin (1984) shows that a Cournot tatonnement process converges globally to the optimal solution for "nice" games (Corollary of Lemmas 1 and 2 in Moulin (1984), p 91) provided that the solution set is a non-empty and compact metric space. As shown by Lemma 2, these conditions hold. Further, the game corresponding to the reaction functions $\hat{K}_{i}^{*}\left(\hat{K}_{-i}, \tilde{e}\right)$ and $\hat{K}_{-i}^{*}\left(\hat{K}_{i}, \tilde{e}\right)$ is "nice" in Moulin's sense provided that the objective function is strictly quasi-concave. The SC condition $f_{\tilde{D}}(x)>0, \forall x \in\left[0, \max \left\{K_{1}^{C}, K_{2}^{C}\right\}\right]$ assures this. In settings in which SC does not hold, one can approximate the original game with games that do satisfy SC whose solutions converge to the optimal solution of the original problem (e.g., subtracting $\epsilon\left(\hat{K}_{1}^{2}+\hat{K}_{2}^{2}\right)$ from the original profit function yields an approximation which, because of the uniqueness and continuity of the resulting solution in $\epsilon$, converges to an optimal solution for the original problem as $\epsilon$ approaches 0 ).

Proof of Proposition 5. Define $\hat{\Pi}_{K}(\tilde{D}, \tilde{e})$ as a firm's expected profit under cap-and-trade when it invests in the optimal emissions tax capacity portfolio, $K_{1}^{*}(\tau)$ and $K_{2}^{*}(\tau)$. From Equations (5) and (6),

$$
\begin{aligned}
\left.\frac{\partial \hat{\Pi}_{K}(\tilde{D}, \tilde{e})}{\partial \tilde{e}}\right|_{\tilde{e} \in \tilde{e}_{i}}= & -\left(\alpha_{i}-\omega \alpha_{[-i]}\right) \mathbb{E}_{\tilde{D}}\left[\tilde{D} \mid \tilde{D}<K_{i}^{*}(\tau)\right] \operatorname{Pr}\left(\tilde{D}<K_{i}^{*}(\tau)\right) \\
& -\left[\left(\alpha_{i}-\omega \alpha_{[-i]}\right) K_{i}^{*}(\tau)+\alpha_{-i}(1-\omega) \mathbb{E}_{\tilde{D}}\left[\min \left(K_{-i}^{*}(\tau), \tilde{D}-K_{i}^{*}(\tau)\right) \mid \tilde{D} \geq K_{i}^{*}(\tau)\right]\right] \operatorname{Pr}\left(\tilde{D} \geq K_{i}^{*}(\tau)\right),
\end{aligned}
$$

and that

$\left.\frac{\partial \hat{\Pi}_{K}(\tilde{D}, \tilde{e})}{\partial \tilde{e}}\right|_{\tilde{e} \in \tilde{e}_{3, i}}=-\left(\alpha_{i}-\omega \alpha_{[-i]}\right) \mathbb{E}_{\tilde{D}}\left[\tilde{D} \mid \tilde{D}<K_{i}^{*}(\tau)\right] \operatorname{Pr}\left(\tilde{D}<K_{i}^{*}(\tau)\right)-\left(\alpha_{i}-\omega \alpha_{[-i]}\right) K_{i}^{*}(\tau) \operatorname{Pr}\left(\tilde{D} \geq K_{i}^{*}(\tau)\right)$.

It follows that $\hat{\Pi}_{K}(\tilde{D}, \tilde{e})$ is piecewise convex in $e$. Consequently, by Jensen's Inequality, $\hat{\Pi}_{K}(\tilde{D}, \tilde{e}) \geq \Pi\left(\tilde{D}, \mu_{\tilde{e}}\right)$. Through profit maximization, $\hat{\Pi}(\tilde{D}, \tilde{e}) \geq \hat{\Pi}_{K}(\tilde{D}, \tilde{e})$.

Proof of Corollary 1. To show $\hat{\Pi}(\tilde{D}, \tilde{e})>\Pi(\tilde{D}, \tau)$ if $\exists i \mid \operatorname{Pr}\left(\tilde{e}>\frac{p^{B}+r+\omega b_{[2]}-b_{i}}{\alpha_{i}-\omega \alpha_{[2]}}\right)>0, \hat{K}_{i}^{*}(\tilde{e})>0$, define $\hat{\Pi}_{K}$ and $\hat{\pi}_{K}$ as the expected profit and expected operating margin under cap-and-trade when the firm's capacities are equal to the optimal capacity decisions under emissions tax.

From (1), the second stage solution in the tax setting prior to the resolution of uncertainties is

$$
\mathbb{E}_{\tilde{D}}[\pi]=\mathbb{E}_{\tilde{D}}\left[q_{[1]}^{*}(\tilde{D})\right] \eta_{[1]}(\tau)+\mathbb{E}_{\tilde{D}}\left[q_{[2]}^{*}(\tilde{D})\right] \eta_{[2]}(\tau)-r \mathbb{E}_{\tilde{D}}[\tilde{D}]-\sum_{i=1}^{2} \gamma_{i} K_{i}^{*}(\tau) .
$$

Since we have assumed that $\mu_{\tilde{e}}=\tau$, we can rewrite (21) as:

$$
\mathbb{E}_{\tilde{D}}[\pi]=\mathbb{E}_{\tilde{D}}\left[q_{[1]}^{*}(\tilde{D})\right] \eta_{[1]}\left(\mu_{\tilde{e}}\right)+\mathbb{E}_{\tilde{D}}\left[q_{[2]}^{*}(\tilde{D})\right] \eta_{[2]}\left(\mu_{\tilde{e}}\right)-r \mathbb{E}_{\tilde{D}}[\tilde{D}]-\sum_{i=1}^{2} \gamma_{i} K_{i}^{*}\left(\mu_{\tilde{e}}\right)
$$


With $\bar{e}_{[1]}=\frac{p^{B}+r+\omega b_{[2]}-b_{[1]}}{\alpha_{[1]}-\omega \alpha_{[2]}}$ and $\bar{e}_{[2]}=\frac{p^{B}+r+(\omega-1) b_{[2]}}{(1-\omega) \alpha_{[2]}}$, the threshold at which it becomes unprofitable to operate technology [1] and [2], respectively, re-write (22) as the conditional expectation

$$
\begin{aligned}
\mathbb{E}_{\tilde{D}}[\pi]= & \sum_{i=1}^{2} \mathbb{E}_{\tilde{D}}\left[q_{[i]}^{*}(\tilde{D})\right] \operatorname{Pr}\left(\tilde{e}<\bar{e}_{[i]}\right) \eta_{[i]}\left(\mathbb{E}_{\tilde{e}}\left(\tilde{e} \mid \tilde{e}<\bar{e}_{[i]}\right)\right) \\
& +\sum_{i=1}^{2} \mathbb{E}_{\tilde{D}}\left[q_{[i]}^{*}(\tilde{D})\right] \operatorname{Pr}\left(\tilde{e} \geq \bar{e}_{[i]}\right) \eta_{[i]}\left(\mathbb{E}_{\tilde{e}}\left(\tilde{e} \mid \tilde{e} \geq \bar{e}_{[i]}\right)\right)-r \mathbb{E}_{\tilde{D}}[\tilde{D}]-\sum_{i=1}^{2} \gamma_{i} K_{i}^{*}\left(\mu_{\tilde{e}}\right) .
\end{aligned}
$$

A firm operating the optimal emission tax capacity portfolio under a cap-and-trade regime generates expected operating margins symmetric to (23),

$$
\begin{aligned}
\mathbb{E}_{\tilde{D}, \tilde{e}}\left[\hat{\pi}_{K}\right]= & \sum_{i=1}^{2} \mathbb{E}_{\tilde{D}}\left[\hat{q}_{[i]}^{*}(\tilde{D})\right] \operatorname{Pr}\left(\tilde{e}<\bar{e}_{[i]}\right) \eta_{[i]}\left(\mathbb{E}_{\tilde{e}}\left(\tilde{e} \mid \tilde{e}<\bar{e}_{[i]}\right)\right) \\
& +\sum_{i=1}^{2} \mathbb{E}_{\tilde{D}}\left[\hat{q}_{[i]}^{*}(\tilde{D})\right] \operatorname{Pr}\left(\tilde{e} \geq \bar{e}_{[i]}\right) \eta_{[i]}\left(\mathbb{E}_{\tilde{e}}\left(\tilde{e} \mid \tilde{e} \geq \bar{e}_{[i]}\right)\right)-r \mathbb{E}_{\tilde{D}}[\tilde{D}]-\sum_{i=1}^{2} \gamma_{i} K_{i}^{*}\left(\mu_{\tilde{e}}\right) .
\end{aligned}
$$

When $p(\tau)+r-b_{i}-\alpha_{i} e \leq 0$, then technology $i \in N \backslash \ddot{N}$, and $\hat{q}_{i}=0$ by (5). Therefore, (24) becomes

$$
\mathbb{E}_{\tilde{D}, \tilde{e}}\left[\hat{\pi}_{K}\right]=\sum_{i=1}^{2} \mathbb{E}_{\tilde{D}}\left[\hat{q}_{[i]}^{*}(\tilde{D})\right] \operatorname{Pr}\left(\tilde{e}<\bar{e}_{[i]}\right) \eta_{[i]}\left(\mathbb{E}_{\tilde{e}}\left(\tilde{e} \mid \tilde{e}<\bar{e}_{[i]}\right)\right)-r \mathbb{E}_{\tilde{D}}[\tilde{D}]-\sum_{i=1}^{2} \gamma_{i} K_{i}^{*}\left(\mu_{\tilde{e}}\right) .
$$

When $p(\tau)+r-b_{i}-\alpha_{i} e>0$, then technology $i \in \ddot{N}$ and $\hat{q}_{i}=q_{i}$ by (5) and (2). As a consequence, by $(23)$ and $(25), \mathbb{E}_{\tilde{D}, \tilde{e}}\left[\hat{\pi}_{K}\right] \geq \mathbb{E}_{\tilde{D}}[\pi]$ is equivalent to

$$
0 \geq \sum_{i=1}^{2} \mathbb{E}_{\tilde{D}}\left[q_{[i]}^{*}(\tilde{D})\right] \operatorname{Pr}\left(\tilde{e} \geq \bar{e}_{[i]}\right) \eta_{[i]}\left(\mathbb{E}_{\tilde{e}}\left(\tilde{e} \mid \tilde{e} \geq \bar{e}_{[i]}\right)\right),
$$

which holds strictly if $\operatorname{Pr}\left(\tilde{e}>\bar{e}_{[i]}\right)>0, \alpha_{[i]}-\omega \alpha_{[2]}>0, K_{i}>0$, and $\operatorname{Pr}\left(\tilde{D}>K_{-i}\right)>0$ for any $i$. Given that $\mathbb{E}_{\tilde{D}, \tilde{e}}\left[\hat{\pi}_{K}\right]$ and $\mathbb{E}_{\tilde{D}}[\pi]$ are derived from identical capacity portfolios, investments costs are identical, so $\hat{\Pi}_{K}(\tilde{D}, \tilde{e})>\Pi(\tilde{D}, \tau)$. Further, $\hat{\Pi}(\tilde{D}, \tilde{e})>\hat{\Pi}_{K}(\tilde{D}, \tilde{e})$ through profit maximization. Therefore, $\hat{\Pi}(\tilde{D}, \tilde{e}) \geq \Pi(\tilde{D}, \tau)$.

It is also true that, if $\hat{\Pi}_{K}(\tilde{D}, \tilde{e})>\Pi(\tilde{D}, \tau)$ due to the option not to operate, then $\exists i \mid \operatorname{Pr}(\tilde{e}>$ $\left.\frac{p^{B}+r+\omega b_{[2]}-b_{i}}{\alpha_{i}-\omega \alpha_{[2]}}\right)>0, \alpha_{[i]}-\omega \alpha_{[2]}>0, \hat{K}_{i}^{*}(\tilde{e})>0$ and $\operatorname{Pr}\left(\tilde{D}>\hat{K}_{-i}\right)>0$ if $\xi(e, i)=[2]$. This is evident through the following contradiction. Assume $\nexists i \mid \operatorname{Pr}\left(\tilde{e}>\frac{p^{B}+r+\omega b_{[2]}-b_{i}}{\alpha_{i}-\omega \alpha_{[2]}}\right)>0, \alpha_{[i]}-\omega \alpha_{[2]}<0, \hat{K}_{i}^{*}(\tilde{e})>$ 0 and $\operatorname{Pr}\left(\tilde{D}>\hat{K}_{-i}\right)>0$ if $\xi(e, i)=[2]$. Then $\eta_{i}(e)>0 \forall e$, or $q_{i}=0 \forall d$. Therefore, $\hat{\Pi}_{K}(\tilde{D}, \tilde{e})=\Pi(\tilde{D}, \tau)$ $\forall e$, which is a contradiction.

Proof of Corollary 2. The result that $\hat{\Pi}(\tilde{D}, \tilde{e})>\hat{\Pi}\left(\tilde{D}, \mu_{e}\right)$ if $\hat{K}_{i}>0, \hat{K}_{-i}>0, \operatorname{Pr}\left(\tilde{D}<\hat{K}_{i}+\right.$ $\left.\hat{K}_{-i}\right)>0$, and $\operatorname{Pr}\left(\tilde{e}>\left(b_{i}-b_{-i}\right) /\left(\alpha_{-i}-\alpha_{i}\right)\right) \in(0,1)$ can be shown directly. To isolate the effect of dispatch flexibility (i.e., avoid confounding it with the option to shutown), assume all demand is served except that which exceeds the firm's total capacity $\hat{K}_{i}+\hat{K}_{-i}$. Wlog, assume $\eta_{i}(0)>\eta_{-i}(0)$, 
i.e., type $i$ is the dirty technology, and define $e_{s}$ as the break-even emissions price between type $i$ and type $-i$; i.e., $e_{s}=\left(b_{i}-b_{-i}\right) /\left(\alpha_{-i}-\alpha_{i}\right)$.

There are two cases to consider: i) where type $i$ is preferred in merit order at emissions price $\mu_{e}$; and ii) where type $-i$ is preferred in merit order at emissions price $\mu_{e}$. Equation (26) proves the first case, with $\hat{\Pi}(\tilde{D}, \tilde{e})-\hat{\Pi}\left(\tilde{D}, \mu_{e}\right)=\Delta_{\hat{\Pi}}$ where

$$
\begin{aligned}
\Delta_{\hat{\Pi}}= & \operatorname{Pr}\left(\tilde{e}>e_{s}\right)\left[\eta_{-i}\left(\tilde{e} \mid \tilde{e}>e_{s}\right)-\eta_{i}\left(\tilde{e} \mid \tilde{e}>e_{s}\right)\right] \mathbb{E}_{\tilde{D}}\left[\min \left(\tilde{D}, \hat{K}_{-i}\right)-\min \left(\left(\tilde{D}-\hat{K}_{i}\right)^{+}, \hat{K}_{-i}\right)\right] \\
& \left.-\operatorname{Pr}\left(\tilde{e}>e_{s}\right)\right)\left[\eta_{i}\left(\tilde{e} \mid \tilde{e}>e_{s}\right)-\eta_{-i}\left(\tilde{e} \mid \tilde{e}>e_{s}\right)\right] \mathbb{E}_{\tilde{D}}\left[\min \left(\tilde{D}, \hat{K}_{i}\right)-\min \left(\left(\tilde{D}-\hat{K}_{-i}\right)^{+}, \hat{K}_{i}\right)\right]>0
\end{aligned}
$$

The case where type $-i$ is preferred in merit order at emissions price $\mu_{e}$ is symmetric.

It can also be shown through contradiction that $\hat{K}_{i}>0, \hat{K}_{-i}>0, \operatorname{Pr}\left(\tilde{D}<\hat{K}_{i}+\hat{K}_{-i}\right)>0$, and $\operatorname{Pr}\left(\tilde{e}>\left(b_{i}-b_{-i}\right) /\left(\alpha_{-i}-\alpha_{i}\right)\right) \in(0,1) \forall i$ if $\hat{\Pi}(\tilde{D}, \tilde{e})>\hat{\Pi}\left(\tilde{D}, \mu_{e}\right)$ due to dispatch flexibility. Assume $\hat{\Pi}(\tilde{D}, \tilde{e})>\hat{\Pi}\left(\tilde{D}, \mu_{e}\right)$ and that $\hat{K}_{i}=0$, or $\hat{K}_{-i}=0$, or $\operatorname{Pr}\left(\tilde{D}<\hat{K}_{i}+\hat{K}_{-i}\right)=0$, or $\operatorname{Pr}\left(\tilde{e}>\left(b_{i}-\right.\right.$ $\left.\left.b_{-i}\right) /\left(\alpha_{-i}-\alpha_{i}\right)\right)=0$, or $\operatorname{Pr}\left(\tilde{e}>\left(b_{i}-b_{-i}\right) /\left(\alpha_{-i}-\alpha_{i}\right)\right)=1$. In $(26)$, if $\hat{K}_{i}=0$, or $\hat{K}_{-i}=0$, or $\operatorname{Pr}(\tilde{D}<$ $\left.\hat{K}_{i}+\hat{K}_{-i}\right)=0$, then the third term in both lines is 0 . Therefore $\Delta_{\hat{\Pi}}=0$, which is a contradiction. Likewise, if $\operatorname{Pr}\left(\tilde{e}>\left(b_{i}-b_{-i}\right) /\left(\alpha_{-i}-\alpha_{i}\right)\right)=0$, then the first term in both lines of (26) is 0 , and again $\Delta_{\hat{\Pi}}=0$, which is also a contradiction. If $\operatorname{Pr}\left(\tilde{e}>\left(b_{i}-b_{-i}\right) /\left(\alpha_{-i}-\alpha_{i}\right)\right)=1$, then type $-i$ would be preferred in merit order and the case symmetric to (26) would apply where $\operatorname{Pr}\left(\tilde{e}<e_{s}\right)=0$ would result in $\Delta_{\hat{\Pi}}=0$, again a contradiction.

Proof of Corollary 3. The result follows directly from the derivatives

$$
\frac{\partial K_{[1]}^{*}(\tau)}{\partial \tau}=\frac{\left(\beta_{[1]}+\gamma_{[1]}-\beta_{[2]}-\gamma_{[2]}\right)\left(\alpha_{[2]}-\alpha_{[1]}\right)}{f_{\tilde{D}}\left(1-\frac{\beta_{[1]}+\gamma_{[1]}-\beta_{[2]}-\gamma_{[2]}}{\eta_{[1]}(\tau)-\eta_{[2]}(\tau)}\right)\left(\eta_{[1]}(\tau)-\eta_{[2]}(\tau)\right)^{2}},
$$

and

$$
\frac{\partial K_{[2]}^{*}(\tau)}{\partial \tau}=-\frac{\left(\beta_{[2]}+\gamma_{[2]}\right)(1-\omega) \alpha_{[2]}}{f_{\tilde{D}}\left(1-\frac{\beta_{[2]}+\gamma_{[2]}}{\eta_{[2]}(\tau)}\right)\left(\eta_{[2]}(\tau)\right)^{2}}-\frac{\left(\beta_{[1]}+\gamma_{[1]}-\beta_{[2]}-\gamma_{[2]}\right)\left(\alpha_{[2]}-\alpha_{[1]}\right)}{f_{\tilde{D}}\left(1-\frac{\beta_{[1]}+\gamma_{[1]}-\beta_{[2]}-\gamma_{[2]}}{\eta_{[1]}(\tau)-\eta_{[2]}}\right)\left(\eta_{[1]}(\tau)-\eta_{[2]}(\tau)\right)^{2}} .
$$

As a necessary condition for an interior solution $\beta_{[1]}+\gamma_{[1]}>\beta_{[2]}+\gamma_{[2]}$. By the definition of merit ordering, $\eta_{[1]}(\tau)>\eta_{[2]}(\tau)$.

When type 1 is preferred in merit order (i.e., it is type [1]), $\alpha_{[1]}>\alpha_{[2]}$ and it follows that (27) is non-positive. When type 1 is not preferred in merit order (i.e., it is type [2]), $\alpha_{[2]}>\alpha_{[1]}$ and it follows that (28) is non-positive. As a consequence the result of type 1 monotonically decreasing in $\tau$ holds.

When type 2 is not preferred in merit order (i.e., it is type [2]), $\alpha_{[2]}<\alpha_{[1]}$ and the RHS of (28) is non-positive only when

$$
\frac{\alpha_{1}-\alpha_{2}}{(1-\omega) \alpha_{2}} \leq \frac{f_{\tilde{D}}\left(1-\frac{\beta_{1}+\gamma_{1}-\beta_{2}-\gamma_{2}}{\eta_{1}(\tau)-\eta_{2}(\tau)}\right)}{f_{\tilde{D}}\left(1-\frac{\beta_{2}+\gamma_{2}}{\eta_{2}(\tau)}\right)} \frac{\beta_{2}+\gamma_{2}}{\beta_{1}+\gamma_{1}-\beta_{2}-\gamma_{2}} \frac{\left(\eta_{1}(\tau)-\eta_{2}(\tau)\right)^{2}}{\left(\eta_{2}(\tau)\right)^{2}},
$$


and the result for Corollary $3 \mathrm{~b}$ follows. When type 2 is preferred in merit order (i.e., it is type [1]), $\alpha_{[1]}<\alpha_{[2]}$ and it follows that (27) is non-negative (proving Corollary 3c).

Proof of Corollary 4. To simplify analysis, we differentiate with respect to $\beta_{2}$ and $b_{2}$, understanding that a per unit subsidy would decrease either parameter. In a single technology portfolio, total capacity is defined by $K_{[i]}^{T}(\tau)$. A subsidy of technology $i$ increases total capacity,

$$
-\frac{\partial K_{[i]}^{T}(\tau)}{\partial b_{[i]}}=\frac{(1-\omega)\left(\beta_{[i]}+\gamma_{[i]}\right)}{f_{\tilde{D}}\left(1-\frac{\beta_{[i]}+\gamma_{[i]}}{\eta_{[i]}(\tau)}\right) \eta_{[i]}(\tau)^{2}}>0, \text { and }-\frac{\partial K_{[i]}^{T}(\tau)}{\partial \beta_{[i]}}=\frac{1}{f_{\tilde{D}}\left(1-\frac{\beta_{[i]}+\gamma_{[i]}}{\eta_{[i]}(\tau)}\right) \eta_{[i]}(\tau)}>0 .
$$

In a mixed portfolio, total capacity is defined by $K_{[2]}^{T}(\tau)$. Subsidizing the least preferred merit order technology, type [2], increases total capacity as in (29) with $i=2$. Subsidizing the preferred type leaves total capacity unchanged, $\partial K_{[2]}^{T}(\tau) / \partial b_{[1]}=\partial K_{[2]}^{T}(\tau) / \partial \beta_{[1]}=0$.

Proof of Corollary 5. When type 1 is preferred in merit order, increases in an investment subsidy $\delta$ are equivalent to decreases of $\delta$ in $\beta_{[2]}$. Therefore, the total emissions potential of capacity increases in investment subsidy when

$$
\begin{aligned}
\frac{\partial\left(\alpha_{[1]} K_{[1]}^{*}(\tau)+\alpha_{[2]} K_{[2]}^{*}(\tau)\right)}{\partial \beta_{[2]}}= & \alpha_{[1]}\left(\frac{1}{f_{\tilde{D}}\left(1-\frac{\beta_{[1]}+\gamma_{[1]]}-\beta_{[2]}-\gamma_{[2]}}{\eta_{[1]}(\tau)-\eta_{[2]}(\tau)}\right)\left(\eta_{[1]}(\tau)-\eta_{[2]}(\tau)\right)}\right) \\
& -\alpha_{[2]}\left(\frac{1}{f_{\tilde{D}}\left(1-\frac{\beta_{[2]}+\gamma_{[2]}}{\eta_{[2]}(\tau)}\right)\left(\eta_{[2]}(\tau)\right)}+\frac{1}{f_{\tilde{D}}\left(1-\frac{\beta_{[1]]}+\gamma_{[1]}-\beta_{[2]}-\gamma_{[2]}}{\eta_{[1]}(\tau)-\eta_{[2]}(\tau)}\right)\left(\eta_{[1]}(\tau)-\eta_{[2]}(\tau)\right)}\right) \leq 0,
\end{aligned}
$$

which holds only under the condition given in Corollary 5a.

The total emissions potential of capacity increases in production subsidy when

$$
\begin{aligned}
\frac{\partial\left(\alpha_{[1]} K_{[1]}^{*}(\tau)+\alpha_{[2]} K_{[2]}^{*}(\tau)\right)}{\partial b_{[2]}}= & \alpha_{[1]}\left(\frac{\beta_{[1]}+\gamma_{[1]}-\beta_{[2]}-\gamma_{[2]}}{f_{\tilde{D}}\left(1-\frac{\beta_{[1]}+\gamma_{[1]-}-\beta_{[2]}-\gamma_{[2]}}{\eta_{[1]}(\tau)-\eta_{[2]}(\tau)}\right)\left(\eta_{[1]}(\tau)-\eta_{[2]}(\tau)\right)^{2}}\right) \\
& -\alpha_{[2]}\left(\frac{\left(\beta_{[2]}+\gamma_{[2]}\right)(1-\omega)}{f_{\tilde{D}}\left(1-\frac{\beta_{[2]}+\gamma_{[2]}}{\eta_{[2]}(\tau)}\right)\left(\eta_{[2]}(\tau)\right)^{2}}+\frac{\beta_{[1]}+\gamma_{[1]}-\beta_{[2]}-\gamma_{[2]}}{f_{\tilde{D}}\left(1-\frac{\beta_{[1]}+\gamma_{[1]}-\beta_{[2]}-\gamma_{[2]}}{\eta_{[1]}(\tau)-\eta_{[2]}(\tau)}\right)\left(\eta_{[1]}(\tau)-\eta_{[2]}(\tau)\right)^{2}}\right) \leq 0
\end{aligned}
$$

which holds only under the condition given in Corollary 5b. 